\title{
Interactional convergence in conversational storytelling: when reported speech is a cue of alignment and/or affiliation
}

\section{Mathilde Guardiola * and Roxane Bertrand}

Laboratoire Parole et Langage UMR 7309, CNRS, Aix Marseille Université, Aix-en-Provence, France

Edited by:

Molly Babel, University of British

Columbia, Canada

Reviewed by:

Olivier Le Guen, CIESAS, Mexico

Jennifer Abel, University of British

Columbia, Canada

*Correspondence:

Mathilde Guardiola, Laboratoire

Parole et Langage, UMR 7309 ,

CNRS and Aix-Marseille Université,

5 avenue Pasteur, 13604,

Aix-en-Provence cedex, France

e-mail: mathilde.guardiola@Ipl-aix.fr
This paper investigates how and when interactional convergence is established by participants in conversation. We analyze sequences of storytelling using an original method that combines Conversation Analysis and a corpus-based approach. In storytelling, the participant in the position of "listener" is expected to produce either generic or specific responses adapted to the storyteller's narrative. The listener's behavior produced within the current activity is a cue of his/her interactional alignment. We show here that the listener can produce a specific type of (aligned) response, which we term a reported speech utterance in echo. The participant who is not telling the story is nonetheless able to animate the characters, while reversing the usual asymmetric roles of storyteller and listener. The use of this device is a way for the listener to display his/her stance toward the events told by the storyteller. If the listener's stance is congruent with that of the storyteller, this reveals a high degree of affiliation between the participants. We present seventeen excerpts from a collection of 94 instances of Echo Reported Speech (ERS) which we examined using the concepts of alignment and affiliation in order to show how different kinds of convergent sequences are constructed. We demonstrate that this phenomenon is mainly used by the listener to align and affiliate with the storyteller by means of reformulative, enumerative, or overbidding ERS. We also show that in affiliative sequences, reported speech can be used by the listener in a humorous way in order to temporarily disalign. This disalignment constitutes a potential starting point for an oblique sequence, which, if accepted and continued by the storyteller, gives rise to a highly convergent sequence.

Keywords: conversation, convergence, alignment, affiliation, similarity, storytelling, reported speech, French

\section{INTRODUCTION}

The goal of this paper is to describe the resources and means used by participants to create convergent sequences in face-toface interactions in French. Since Sacks and colleagues published the first papers (see Sacks et al., 1974, among others) in the field of Conversational Analysis, it has been demonstrated that a face-to-face interaction is a collaborative production by all the participants. For example, while the main speaker is talking, the listener plays an active role through short utterances or backchannel signals to show sustained attention and understanding of the discourse (Schegloff, 1982). Simultaneously, backchannel signals provide information about the processes the speaker uses to mark important steps in the discourse (Fox Tree, 1999). Although this collaborative production or joint-construction is a necessary requirement for successful interaction (Clark, 1996), it does not necessarily produce convergent sequences. Here we describe the specific points that allow these sequences to emerge.

We rely on the notions of alignment and affiliation, as defined in Conversational Analysis by Stivers (2008), to investigate when and how convergent sequences can appear in conversation. Drawing on conversational storytelling sequences, we focus on reported speech, i.e., speech or thoughts attributed to another person and another context (Holt, 1996; Bolden, 2004). We attempt to demonstrate that for the listener who uses it, this discursive device, usually expressed by the main speaker, constitutes a good candidate for alignment and affiliation.

The Conversational Analysis framework (henceforth $C A$ ) aims to describe social activities in which speakers attempt to accomplish goals in interaction. Among the various approaches within CA, we adopt the Interactional Linguistics (IL) approach (CouperKuhlen and Selting, 1996; Barth-Weingarten et al., 2010, among others). This approach provides a systematic method for studying how and what kind of resources (prosodic, syntactic, semantic, gestural, and so on) participants deploy to manage talk-ininteraction. From an $I L$ perspective, the purpose of an interaction is to accomplish actions (questions, repairs) and activities such as story-telling, arguing, disputing, describing, and direction-giving (Selting, 2010). Interactions are heterogeneous; they generally include more than one activity, and participants take on different recognizable discursive roles during different activities that impact the organization of turn-taking (Szczepek Reed, 2010). We chose to focus on convergence within one activity in particular: storytelling. 
Storytelling very frequently occurs in conversation and has been investigated not only to improve the definition of the conversational unit but also to characterize participants' roles and turnmanagement (Selting, 2000). In storytelling, the main speaker needs several Turn-Constructional Units (TCUs) to reach the end of his/her story and to make the transition to another speaker possible [a Transition Relevance Place (TRP)]. Because the storyteller (the main speaker) and the listener have different storytelling roles, storytelling is seen as an asymmetrical activity, but both participants actively participate and work together to construct the narrative.

The main speaker has to respect the expectations that participants have of storytelling. First of all, the speaker has to ensure that he/she can begin to tell the story. A story is a large project (Selting, 2000) implying a long duration, so the main speaker has to be authorized by the listener to tell it. The story itself has to be "tellable": it should present an interest. Moreover, the story has to be told in a specific order that has been described as a succession of formal phases (Labov and Waletzky, 1966). In the first two phases, the orientation and complication phases, the storyteller presents characters and events, respectively. The apex corresponds to the culminating point of the story, after which a kind of evaluation phase can appear. Stories in conversation can also exhibit other phases such as parenthesis or aside (Selting, 2000).

The listener also has to comply with certain expectations. $\mathrm{He} / \mathrm{she}$ is supposed to listen to the story while providing feedback showing ratification of the storyteller in this role, understanding of the ongoing discourse, and the state of shared knowledge, for instance. Bavelas et al. (2000) have shown that the responses produced by the listener in storytelling are so important that the teller cannot tell the story correctly when responses are absent or perturbed. By respecting these obligations, the listener achieves alignment during the activity. Alignment is defined "with respect to the activity in progress" (Stivers, 2008: 34). For our study, a type of aligned behavior by the listener would be to produce responses matching the speaker's expectations. At the beginning of the story, the listener begins to align him/herself as a story recipient using appropriate responses (Jefferson, 1978), for example. More generally, Bavelas et al. (2000) have described listeners' responses as generic or specific: the first simply correspond to responses required by the activity that are sufficiently general to adapt to any type of narrative, while the second are specifically adapted to the ongoing narrative. The authors have shown that specific responses appear later in the narrative than generic ones. In line with these results, a previous study on our French conversational corpus (Guardiola et al., 2012) showed that morpho-syntactically richer responses labeled as specific responses mainly appeared later in the narration. These results suggest that generic responses produced earlier than specific responses require less knowledge of the situation described by the storyteller. In our opinion, generic responses function as continuers or acknowledgements (Schegloff, 1982), which help to show how shared knowledge is elaborated during the initial phases of stories, while specific responses function as assessments (evaluative or attitudinal) once sufficient information about the story has been provided.

The information given by the teller includes his/her own stance on the events, and the stance the listener is expected to have.
Giving affiliative responses, for the listener, thus, means providing the expected stance toward the story. Affiliation is defined as the fact that "the hearer displays support of and endorses the teller's conveyed stance" (Stivers, 2008: 35). Stivers develops the argument that affiliation requires alignment. Since affiliation implies that the participant knows the teller's stance on his/her own story (and knows that a similar stance is the preferred response), it means that the participant has gathered enough information about the story being told, which is shown by displaying alignment.

In this paper, we are interested in exploring the emergence of convergent sequences in terms of the concepts of alignment and affiliation. In any domain, convergence is usually defined as a behavior that becomes more and more similar over the time. For us, a convergent sequence requires preliminary alignment and affiliation, associated with similarity (including at the phonetic, prosodic, syntactic, semantic, lexical, and/or discursive levels). We consider a sequence as convergent when the interactional statuses evolve toward symmetry between participants.

We argue that a single alignment is not sufficient to produce convergent sequences; they also require affiliation. To achieve affiliation, in turn, participants need to share sufficient common ground, which they co-elaborate during the first part of the story: the main speaker gives new information while the listener shows, through generic responses for example, that he/she adds them to his/her own common ground (alignment).

Direct reported speech is a very frequent discursive device used by the storyteller around the apex of the narrative (Holt, 2000; Blondal, 2005). Most of the time, the storyteller, while apparently reporting speech in an objective way, gives many implicit cues of his/her own stance toward the events. The listener then understands the teller's stance and is thus, able to explicitly produce the same stance as the teller, which constitutes the preferred response. This creates a highly affiliative sequence in interaction (Holt, 2000). Storytellers use reported speech in order to elicit affiliation from the listener, and listeners' reactions to reported speech show their affiliation. Reported speech has been described in the literature as a device exhibited by the main speaker for reporting words that have already been uttered in another situation. However, we demonstrate here that listeners themselves use direct reported speech to show their affiliation. The data show that some of the specific responses produced by the listener take the form of direct reported speech utterances produced by the listener, henceforth, "Echo Reported Speech" (ERS). In the cases we study here, the participant who produces the reported speech is not the teller, so he cannot have heard these words before. They thus, have an "inventive" function (see Vincent and Dubois' typology, 1997). But more importantly, by using this device, the listener reveals that the canonical roles played by the storyteller and the listener can be temporarily reversed.

We use a sequential analysis to explore how reported speech offers a way for the listener to exhibit a form of (dis)alignment and (dis)affiliation. In the sequential analysis, an utterance is considered in relation to the preceding and the following turns. The action accomplished by a turn is revealed by the context in which it occurs, but also by the action's consequences on the interactional orientation of the sequence (Hutchby and Wooffitt, 1998). A turn by the listener may or may not be ratified by the storyteller, 
and the storyteller can then orient either toward the listener's turn or toward his/her own previous turns (storytelling), while ignoring the listener's turn.

By analyzing our instances of ERS using the concepts of alignment and affiliation, we provide evidence of the emergence of highly convergent sequences. Instances of ERS are examined in order to study their link with both alignment and affiliation. Stivers (2008) claims that alignment and affiliation are the result of different phenomena, showing for instance that nodding reveals affiliation while a vocal $m h$ reveals alignment. However, we believe that any device can be used for one or both of these dimensions. We thus, demonstrate that the use of the same deviceERS — can result in dissimilarly convergent sequences (local or large-span convergent sequences, or sometimes non-convergent sequences).

In the section Materials and Methods, we present the corpus and the method used. After some descriptive data, the main focus of the section Results and Analysis is the sequential analysis of several examples, which allows us to argue for an interactional description of ERS in terms of alignment and affiliation. In section Discussion, we discuss the implications of these notions on the potential emergence of a convergent sequence, and we present perspectives for further work on interactional convergence.

\section{MATERIALS AND METHODS CORPUS}

The study was lead on the Corpus of Interactional Data (CID) (Bertrand et al., 2008). Figure 1 shows the experimental setup: the corpus (i.e., 8 one-hour French dialogues) was recorded in an anechoic room; each speaker is wearing a microphone; and the positions and proximity of the participants indicates that they are having a conversation.

The participants were given instructions to tell personal stories: unusual stories for half of them, and stories about work conflicts for the other half. This kind of task (telling amusing stories and making complaints) is known to promote the occurrence of reported speech (Holt, 2000). The instructions might have led the participants to engage in an asymmetrical interaction, but this was not the case. The data closely resemble what we consider a natural conversation (Bertrand et al., 2008): the participants did not have a third party to manage turn-taking and were free to negotiate their roles as listeners or tellers. In addition, they were familiar with the place where they were being recorded and knew each other well, allowing them to adopt a very informal style during the interactions.

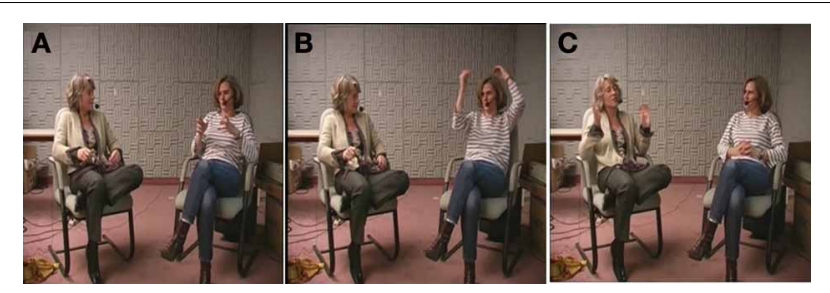

FIGURE 1 | Experimental setup for the CID.

\section{METHODOLOGICAL APPROACH}

Our method combines $I L$ and a corpus-based approach (corpus processing). We adopted this dual approach in order to systematically annotate the phenomena in the corpus. We then drew up a list of occurrences of similar events in our dataset, i.e., a collection of examples, as recommended in CA (Mondada, 2013). However, unlike a $C A$-style transcription that exhibits all the relevant cues (prosodic, gestural, phonetic) on the same line (see (Selting et al., 1998) for the GAT system, adapted from the Jefferson-style transcription system), the transcription used in this work is one of the levels of the annotation process elaborated within the framework of the OTIM project (Blache et al., 2009). Using Praat (Boersma and Weenink, 2009), rich and systematic annotations related to the different linguistic domains, from phonetic to gestural, are provided. For each domain, the link between the annotated phenomena is encoded using an annotation scheme that requires a certain degree of formalization (see below for the annotation scheme used for reported speech). Precise synchronization between the different annotations makes it possible to study the relationships between them.

For the present study, we used the following annotation levels: orthographic transcription, tokens, prosodic units (phrasing) and pitch contours, narratives, morpho-syntactic categories, speech overlap phases and laughter. For each speaker, all of the information is aligned in time with a precision level of one phoneme. This gave us a very precise description of the timing and delay of any phenomenon in the corpus. Considering this, we can study the co-occurrence of several phenomena.

\section{THE ANNOTATION SCHEME USED FOR DIRECT REPORTED SPEECH}

As this study focuses on reported speech, we only present, in Figure 2, the relevant parts of the overall annotation scheme (Blache et al., 2010). The reported speech sequences were annotated along several dimensions:

- Q(uotation)-structure: the (optional) exchange structure, which reveals whether the scene reports speech from one character or more than one character (in a reported dialogue).

- Q-component: the various components of the structure (introductive formula, the different voices, etc.).

- Q-source: the origin of the voices used by the speaker.

- Q-type: the functional type of quotation based on the typology of Vincent and Dubois (1997): Reproduction consists

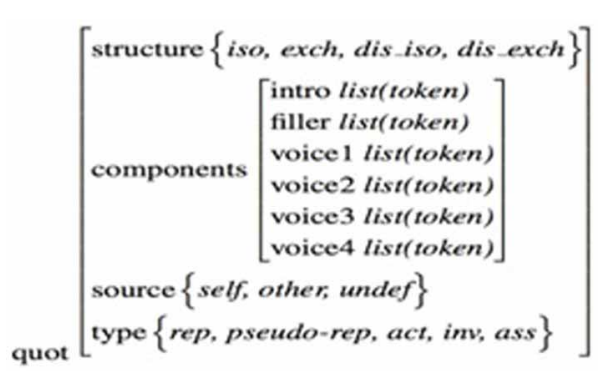

FIGURE 2 | Annotation scheme of direct reported speech in the CID. 
of presenting the reported speech as having already been said in another situation. Pseudo-reproduction corresponds to reported speech for which the previous situation is not clearly identifiable. Assertion is the fact of reporting speech as an authority argument. Actualization is used to report speech that has occurred in several similar situations. In invention, the speaker presents the speech as never having been said.

Reported speech utterances were first located by a transcriber and then annotated by two other experts according to the annotation scheme presented above. The corpus-based method implies several annotators between whom a score of agreement is calculated. For our study, we retained only the cases where the two experts agreed. Reported speech was annotated for each speaker over the course of the whole interaction, regardless of the discursive role of the participant at each point of the interaction.

Once the reported speech was annotated, we conducted a manual turn-by-turn analysis of the sequences ( $C A$ approach). To analyze a turn using this type of analysis, we determined which actions the previous turn achieved and took into account the next turn, which gives cues about how the target turn is received by the participants. This last point raises the question of ratification: to consider that an action has been achieved in interaction, one should carefully observe its possible consequences on the interaction, especially its ratification by the interacting participants.

The results discussed below show how the participants aligned and affiliated using ERS to co-construct convergent sequences in conversation.

\section{RESULTS AND ANALYSIS DESCRIPTIVE DATA}

Let us consider the results of eight dialogues we selected for analysis. Table 1 below shows the number of narratives and the speech production time per speaker, as well as the distribution of reported speech between the storyteller and the listener (ERS).

Out of the 590 quotation structures annotated, we found 94 occurrences of ERS. Every participant (except for the LL-NH pair) used ERS at least once during the interaction. Eight listeners produced at least five reported speech utterances, and in three dialogues each listener used about 15 reported speech utterances, showing how frequently ERS appears in storytelling. Three of the dialogues show an asymmetric ERS distribution, with more occurrences produced by one of the participants (17 vs. 7 for EB-SR, 10 vs. 3 for AC-MB, 5 vs. 2 for IM-ML). One of the listeners $(\mathrm{AC})$ who used more reported speech produced fewer narrative sequences. This listener seemed to adopt the listener role more frequently throughout the dialogue. Lastly, the dialogue where ERS was absent (LL-NH) is atypical in the sense that it contains far fewer narratives than the other dialogues ( 2 and 7 narratives), and one of the participants (LL) did not speak much.

\section{DESCRIPTION OF ECHO REPORTED SPEECH}

As shown in our data, ERS is the listener's invention of what reported speech would sound like at an event where the listener was not present. This type of reported speech was found
Table 1 | Descriptive data for each speaker: narratives, speech time, reported speech and ERS instances.

\begin{tabular}{|c|c|c|c|c|c|c|}
\hline \multirow[t]{2}{*}{ Dialogue } & \multirow[t]{2}{*}{ Speaker } & \multirow[t]{2}{*}{$\begin{array}{l}\text { Narrative } \\
\text { occurrences }\end{array}$} & \multicolumn{2}{|c|}{$\begin{array}{l}\text { Speech time } \\
\text { (in s) }\end{array}$} & \multicolumn{2}{|c|}{$\begin{array}{l}\text { Q_structure } \\
\text { utterances }\end{array}$} \\
\hline & & & $\begin{array}{l}\text { As } \\
\text { narrator }\end{array}$ & $\begin{array}{l}\text { As } \\
\text { listener }\end{array}$ & $\begin{array}{l}\text { Non- } \\
\text { echo }\end{array}$ & $\begin{array}{l}\text { ERS } \\
\text { instances }\end{array}$ \\
\hline \multirow[t]{2}{*}{$\mathrm{AB}-\mathrm{CM}$} & $A B$ & 7 & 911.4 & 108.9 & 45 & 10 \\
\hline & $\mathrm{CM}$ & 6 & 639.5 & 212.1 & 20 & 8 \\
\hline \multirow[t]{2}{*}{ AC-MB } & $A C$ & 8 & 634.4 & 180.0 & 33 & 10 \\
\hline & $\mathrm{MB}$ & 17 & 1304.1 & 61.1 & 51 & 3 \\
\hline \multirow[t]{2}{*}{ AG-YM } & $A G$ & 14 & 606.5 & 71.8 & 30 & 2 \\
\hline & YM & 13 & 485.7 & 101.1 & 47 & 1 \\
\hline \multirow[t]{2}{*}{ AP-LJ } & AP & 10 & 422.4 & 94.0 & 34 & 13 \\
\hline & LJ & 8 & 389.9 & 73.3 & 46 & 13 \\
\hline \multirow[t]{2}{*}{ BX-MG } & $B X$ & 6 & 282.1 & 16.7 & 11 & 2 \\
\hline & MG & 5 & 202.7 & 10.7 & 18 & 1 \\
\hline \multirow[t]{2}{*}{ EB-SR } & EB & 9 & 403.5 & 62.6 & 18 & 17 \\
\hline & $\mathrm{SR}$ & 10 & 681.1 & 41.2 & 37 & 7 \\
\hline \multirow[t]{2}{*}{ IM-ML } & $\mathrm{IM}$ & 13 & 730.6 & 105.8 & 30 & 2 \\
\hline & $M L$ & 12 & 631.3 & 74.44 & 40 & 5 \\
\hline \multirow[t]{2}{*}{ LL-NH } & LL & 2 & 119.1 & 64.92 & 9 & 0 \\
\hline & $\mathrm{NH}$ & 7 & 546.8 & 8.2 & 27 & 0 \\
\hline Total & & 147 & & & 496 & 94 \\
\hline
\end{tabular}

in the middle or at the end of the narrative (around the apex or evaluation phases), as expected. It was produced in the very close environment of reported speech, either during an occurrence or a sequence of canonical direct reported speech produced by the storyteller.

Let us now examine a rather typical case of ERS (Ex1). This extract occurs at the apex of the story, where MB first produces reported speech (in her own voice) to ask a child a question (line 630d). The listener, AC, produces specific responses (lines 991, 992), before producing reported speech with the fictitious voice of the child and answering MB's question (line 993). While doing this, $\mathrm{AC}$ creates a fictitious dialogue between $\mathrm{MB}$ (herself) and the child. $\mathrm{MB}$ then continues her activity of reporting this exchange between them. The use of deixis (line 993) is coherent for storytelling, not for the current recording situation (the dialogue hic et nunc): AC is not speaking with her own voice, so she must be reporting speech.

\section{Ex1_Fr:}

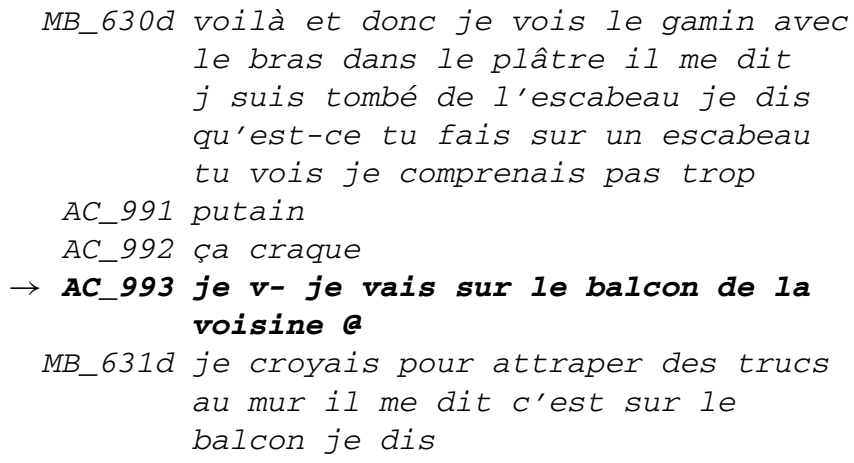




$$
\begin{aligned}
& \text { MB_632d un escabeau sur le balcon mais tu } \\
& \text { es fou c'est hyper dangereux } \\
& \text { MB_633 il me dit non je le fais tous les } \\
& \text { soirs }
\end{aligned}
$$

Ex1_En:

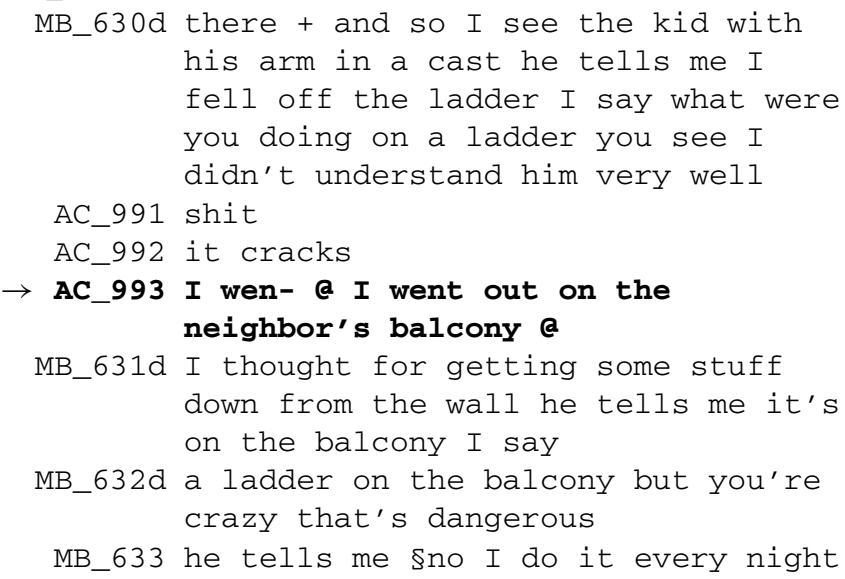

After some evaluative responses, turn 993 presents the characteristics of direct reported speech-change of verbal tense, deictics anchored in the reported situation- although it is produced by the participant who is in the position of receiving the story. This speaker has understood the described situation well enough to be able to continue the narrative, adding reported speech and making the characters talk, even though she had not witnessed the scene. This reported speech is thus, an invention, but it is anchored in the reported situation and specifically oriented toward the previous turn since it answers MB's previous question.

We now turn to the question of how ERS enables listeners to align and affiliate with the ongoing story and allows the conversation participants to initiate a convergent sequence.

\section{SEOUENTIAL ANALYSIS}

The listener mainly produced ERS just after a reported speech utterance produced by the storyteller. In doing so, the listener can either adopt the same voice the narrator was using, use another voice to build a reported dialogue, or even add a different tonality. In some cases, ERS anticipates the storyteller's reported speech production. In other cases, the use of reported speech initiates a new sequence, which will be considered separately.

The examples below (2-6) present the most common occurrences and are the most meaningful for showing affiliation.

\section{Reformulation}

The next two examples show cases of "similar voices" in reformulation.

In Example 2, $\mathrm{AB}$ is telling a story about a friend canceling a movie date. She reports a dialogue between her friend and herself. The ERS in 642 is a reformulation of the reported answer of $A B$, which is a commentary she made at the moment, in the situation being told. Although the ERS doesn't exhibit explicit cues of reported speech, it would be irrelevant in the present dialogue.
It is indeed a reformulation, in a reported way, and expresses the same voice as $\mathrm{AB}$ (line 442). It is an aligned response in that it supports the ongoing story. At the same time, by doing this, CM displays the same stance as $\mathrm{AB}$ toward the event: canceling the date was not a serious problem. This reported speech utterance is thus, an affiliative response to the story told by $\mathrm{AB} . \mathrm{AB}$ can consider this response as a backchannel (BC) signal. In line with Kern (2007), in some cases where a BC is expected, the lack of ratification is equivalent to a minimal ratification via a backchannel. So AB does not need to ratify it, in the sense that it is "normal" that CM's response is aligned and affiliative: if it were not, it would be signaled by a repair sequence. Therefore, in this case, the ERS is ratified by not saying anything.

Ex2_Fr:

$A B \_440$ elle avait une gastro donc elle m'a dit

CM_640 ah ouais

$A B \_441$ je suis malade depuis hier soir et

CM_641 oui

AB_442 je dis C'est pas grave

$\rightarrow$ CM_642 tant pis

AB_443 C'est pas grave C'est pas grave on

fera ciné à un autre moment

Ex2_En:

AB_440 she had a stomach ache so she told me

CM_640 oh yeah

AB_441 I've been sick since last night and

CM_641 yes

AB_442 I say it's no big deal

$\rightarrow$ CM_642 too bad

AB_443 no big deal no big deal we'll go to the movies another time

In some cases not only is the device similar, but so is the prosody and lexicon. In Example 3, IM is telling a story while criticizing the characters (teachers), who take breaks all day long. IM displays her stance by using a specific voice when she reports their (invented) speech (line 581). ML also animates the same figures (line 554) by using similar words and a similar prosodic delivery. The various reported speech occurrences (from both IM and ML) are produced in three intonative units: each is introduced with an open and lengthened "oh," is ended with a rising pitch contour on the penultimate syllable and followed by a high plateau on the final schwa. This prosodic delivery sounds like a Southern French accent but its exaggerated production (Couper-Kuhlen, 1999; Günthner, 1999) contributes to exhibiting the criticism of the characters. By using the same delivery as IM (prosodic stylization, Szczepek Reed, 2006), ML displays the same stance and consequently shows affiliation.

Ex3_Fr:

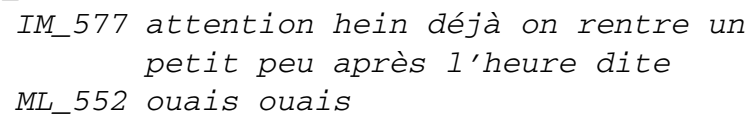




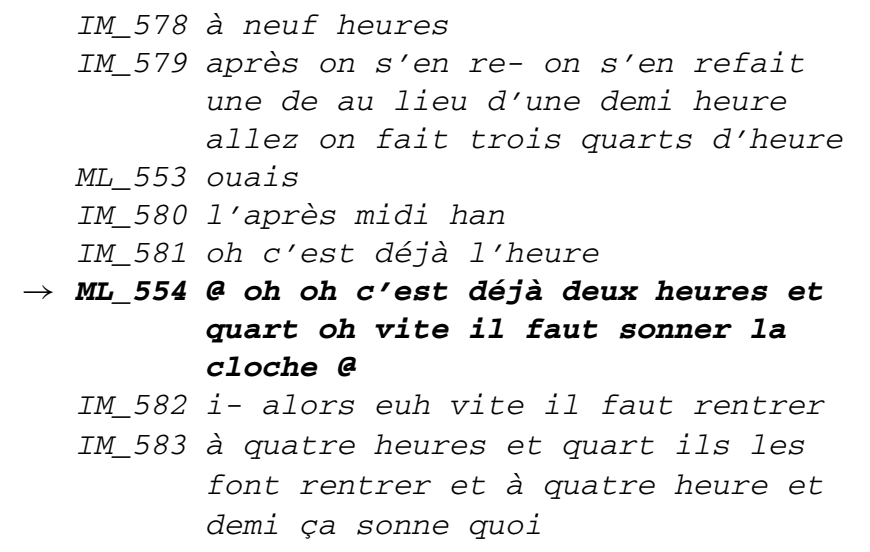

Ex3_En:

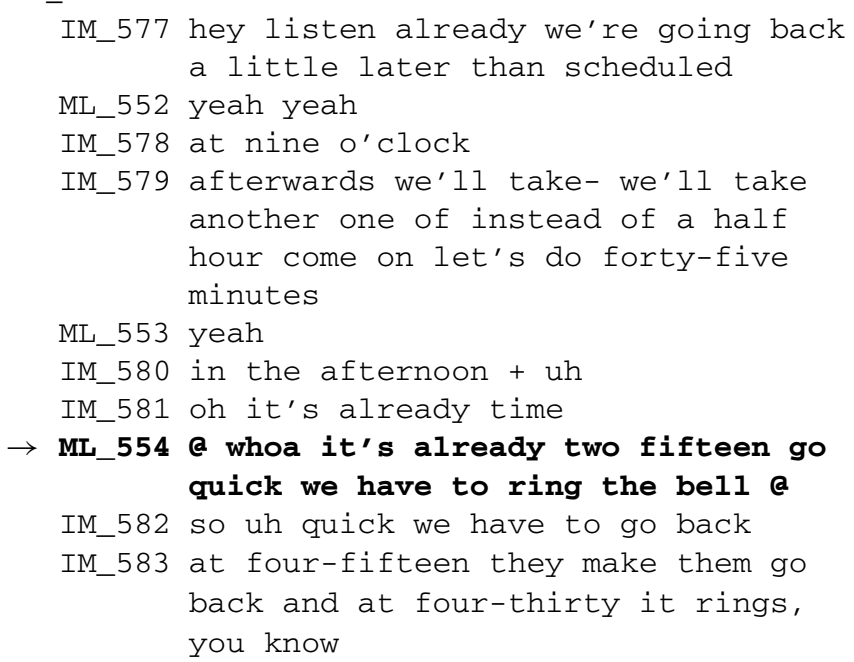

In sum, for the two examples above (2 and 3), one can see that when the listener of a story animates a character, it constitutes an aligned and affiliative response for the ongoing narrative. Since these ERS utterances only reformulate what has just been reported by the storyteller, they do not require any explicit ratification by the storyteller.

\section{Overbidding ERS}

The next example (Ex4) displays another type of affiliative ERS: overbidding ERS. AC is complaining about students' parents. She reports her own speech, which she virtually addresses to the parents. $\mathrm{MB}$ also produces reported speech using the same voice as $\mathrm{AC}$, showing that she has the same stance as $\mathrm{AC}$ toward parents. $\mathrm{MB}$ uses the same sentence structure: imperative tense and formal you. AC ratifies MB's utterance by repeating it and inserting it in her own narrative using "ou/or" which makes MB's proposition a part of AC's story, but not what she first thought. AC repeats it again twice, which suggests that this turn was truly affiliative: the stance displayed by $\mathrm{MB}$ is compatible with AC's own stance and with the content of the narrative.

Ex4_Fr:

$$
\begin{gathered}
\text { AC_617 nous on fait notre boulot on fait } \\
\text { ce qu'on peut mais }
\end{gathered}
$$

\author{
AC_618 neuf cent élèves et si vous avez \\ des problèmes vous allez voir \\ AC_619 faut aller re-gueuler au rectorat \\ vous avez raison allez gueuler au \\ rectorat \\ $\rightarrow$ MB_461d faites des courriers \\ AC_620 ou faites des courriers faites des \\ + faut faire des courriers faut \\ faire des courriers madame
}

Ex4_En:

AC_617 we do our work we do what we can but

AC_618 nine hundred students if you have any problems you'll see

AC_619 have to complain to the Board of Education you're right go complain to the Board of Education

$\rightarrow$ MB_461d send letters

AC_620 or send letters send + have to send letters have to send letters ma' am

\section{Dislocative completion}

The next example (Ex5), illustrates that ERS can also function as a completion elicited by the teller. Speaker AB is telling a story about herself and her friends who went into a nuns' dormitory when she was young. In turn 203, she reports the speech of a friend of hers. Interestingly, she does not complete the "sentence" she was reporting; the incomplete syntactic structure projects a potential continuation. But the following pattern - a filled pause, a silent pause, CM's acknowledgement signal, and a final, long silent pause before the next turn (338) reveals a TRP managed by $\mathrm{AB}: \mathrm{AB}$ has finished talking about the nuns and expresses a wish to continue on another topic (the events themselves). In this TRP, CM does not take the turn. After the long delay, both participants can legitimately take the floor and thus, speak at the same time. CM then produces an ERS (line 338), reporting the end of the reported speech initiated by $\mathrm{AB}$. This is a typical case of completion of a dislocated structure: taken together the parts, uttered, respectively, by the storyteller and the listener, form a coherent whole, as we can see by the anaphora-the pronoun "les/them" corresponds to the antecedent "ces bonnes soeurs/these nuns"-and the verb tense (simple present).

The information added by $\mathrm{CM}$ is not contradictory with what $\mathrm{AB}$ thought, so that $\mathrm{AB}$ repeats it and integrates it in her own discourse, which proves that the response produced by $\mathrm{CM}$ is affiliative.

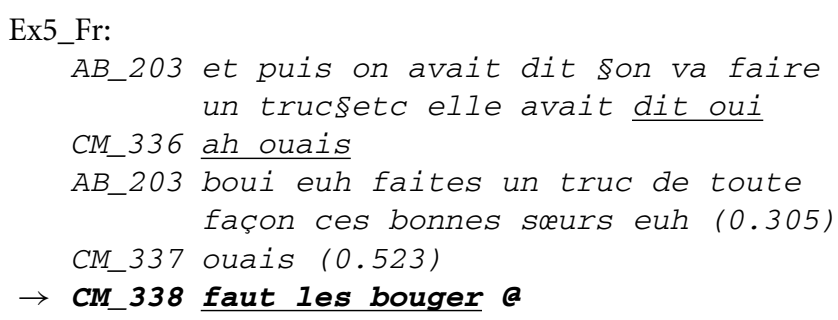




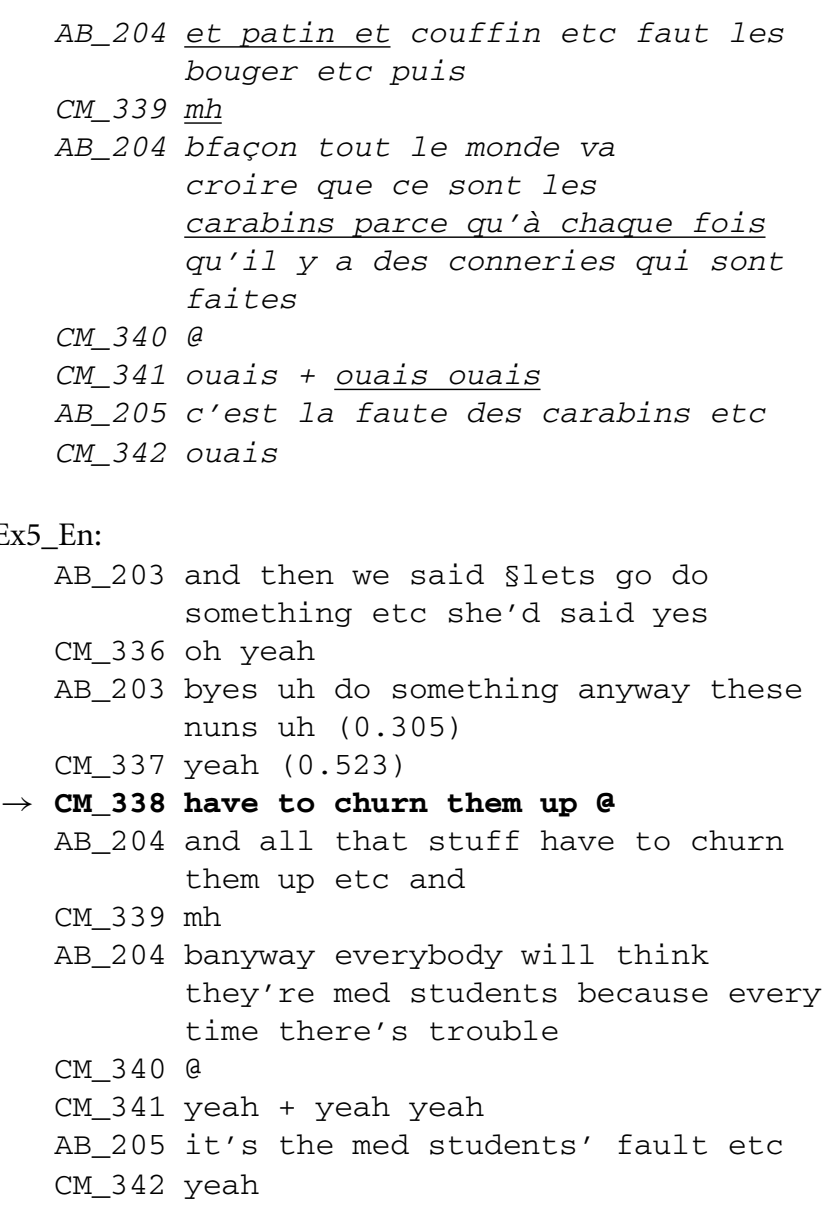

While carrying out the specific action of completing the turn, CM displays her alignment with the current activity: she supports AB's narration. She provides a type of expected behavior, even elicited behavior. Moreover, CM expresses her stance about the story by laughing loudly just after her turn. AB's reaction gives cues about the action accomplished by CM's turn. The turn is made clear by AB's strong ratification: she repeats CM's remark, showing that it was aligned. The sequence also shows affiliation: CM's stance toward the nuns is the same as the one $\mathrm{AB}$ alludes to earlier (nuns are too quiet). By repeating the ERS, $\mathrm{AB}$ integrates it into her own story, as in the previous one.

In sum, Ex4 and 5 illustrate cases of strong convergence, even though they occur over a very short time span. These are cases of what we call "local" convergence. Immediately after the occurrence of the ERS, the storyteller goes back to the asymmetrical activity of storytelling by integrating the proposed reported speech into her current discourse.

\section{Enumerative completion}

Numerous cases of ERS can occur in an enumerative structure. Following Jefferson's (1990) analysis of lists, Selting (2004, 2007) describes enumerative as "a larger three-component structure that the list is the middle part of (...). The three components are: $\mathrm{i} / \mathrm{a}$ projection component (i.e., the formulation of a general point that projects more-to-come), ii/ a list of items, and iii/ a closure of the structure projected by i/ and ii/. The author treats the enumerative structure as a holistic entity or a "gestalt" that can be produced by a single speaker but also jointly by participants" (Selting, 2004: 212).

Reported speech can be used as an item in the enumerative structure. Similarly, ERS can be produced as an item added to the list, generally with the same voice as the storyteller's last occurrence of reported speech.

Example 6 (Figure 3) exhibits such an enumerative structure containing reported speech. IM is telling a story about the attitude of her son's teacher toward his left-handedness. She produces an occurrence of reported speech (line 727), reporting her own voice, and then creates a reported dialogue, reporting the teacher's speech. Figure 3 illustrates that turns 728-729 are composed of a list of several items ( 3 in 728 and 2 in 729) each corresponding to a prosodic unit associated with a typical rising list contour ( $\mathrm{RL}$ or $\mathrm{L}+\mathrm{H} * \mathrm{H} \%$ in auto-segmental metrical terms) (Portes et al., 2007). The occurrence of ERS (line 691) appears as the third component of the enumerative structure (closure) initiated by "et/and" and closed by a discourse marker "quoi/you know" spoken with a falling contour (F or L\%). The listener thus, ended the enumerative structure initiated by the storyteller. This structure was co-elaborated by the participants both discursively and prosodically (as illustrated by Figure 3 ). This case of prosodic complementation is a form of prosodic orientation in which the last falling contour is expected, after the rising contours, to close the enumerative structure (Szczepek Reed, 2006: 61). As a result of the discursive and prosodic orientation, the response is aligned.

In addition, ML's stance toward the events and toward the teacher (critical) is the same as the narrator's, and her response is thus, also affiliative. Like reformulation cases, the storyteller does not always ratify the added affiliative item. The lack of ratification here is equivalent to a basic acceptance, affiliation being the response preferred and expected by the storyteller.

\section{Ex6_Fr (Figure 3):}

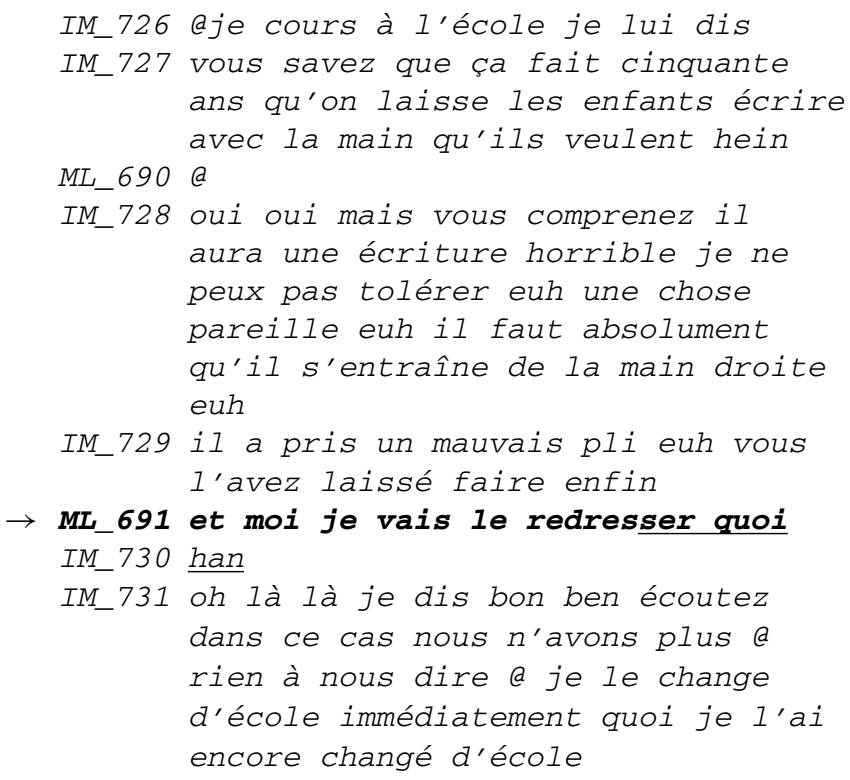




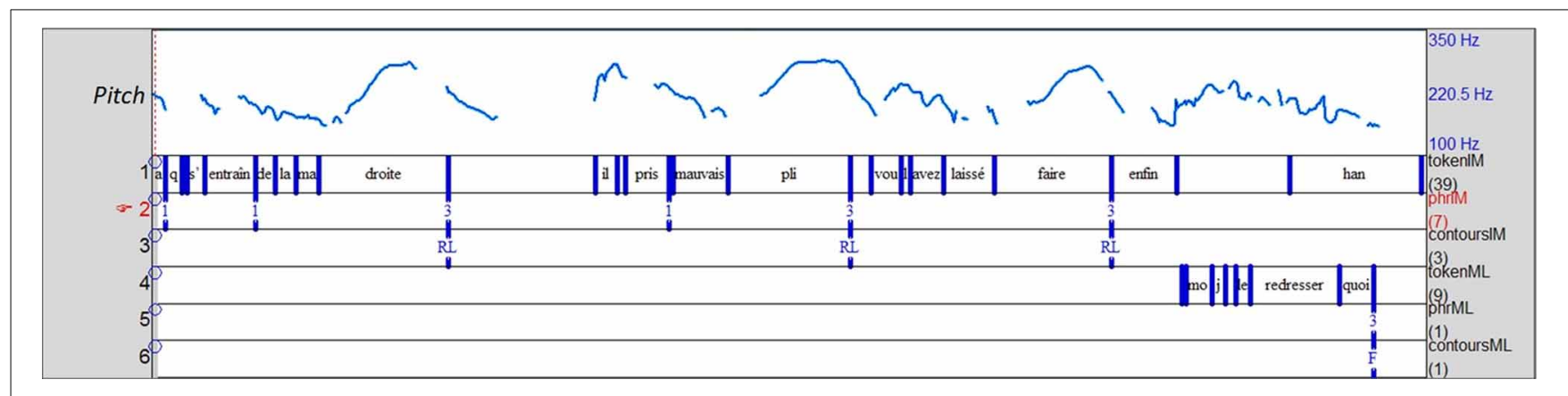

FIGURE 3 | Prosodic complementation in the enumerative structure co-produced by the storyteller (tier1) and the listener (tier4). The last three items -"droite/right," "pli/habit," and "faire/do"- end in an intonative unit (coded 3 on tier2) and are associated with a rising list contour, RL (tier3). The final item produced by the listener (tier4) ends in an intonative unit (coded 3 on tier5) and is associated with a final falling contour, F (tier6).

\section{Ex6_En (Figure 3):}

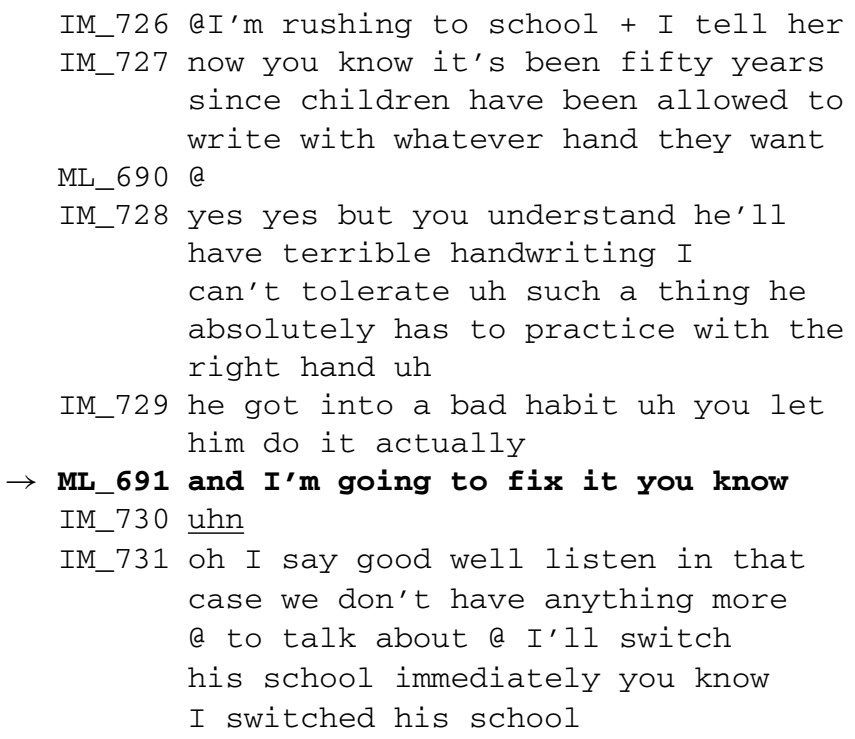

Example 7 (Figure 4) presents another enumerative structure, but with different consequences for the sequence's degree of convergence. $\mathrm{MB}$ is telling a story in which she reports her own speech. The structure is composed of three items, and AC proposes an additional item with a similar prosodic configuration, as shown by Figure 4 . Here, the list effect is created by the reiteration of a typical global configuration in the intonative units from the storyteller. This configuration is characterized by an initial and a final accent that form an accentual arch (Fonagy, 1979; Di Cristo, 1999) that functions as a cohesive mark (Figure 4). The copy of this configuration in the ERS illustrates a case of prosodic matching (Szczepek Reed, 2006). Consequently, the turn is clearly oriented toward MB's previous talk, showing alignment both to the storytelling and the device: a continuation of the enumerative structure and the same (reported) voice in a similar accentual configuration as $\mathrm{MB}$.

AC attempts to display affiliation by reporting MB's speech: she expresses a stance corresponding to MB's, through her use of MB's voice. Despite the opportunity for affiliation, this element not only does not receive an explicit verbal ratification, it is ignored. This can be explained by the fact that it functions as feedback: although it corresponds to prosodic matching on the prosodic figure exhibited (accentual arch), we can see that this configuration not only overlaps with MB's turn but is also in a very compressed pitch range. In contrast, MB's three arches are produced in an increasingly expanded pitch range that seems to function as a turn-holding cue. Moreover, MB's next turn is oriented toward her own previous speech, and not toward AC's turn since 417 is a completion of 416 and thus, cannot complete ERS (475). As a result, the sequence appears as a nonaffiliative sequence, despite AC's attempt to produce an expected stance.

Ex7_Fr (Figure 4):

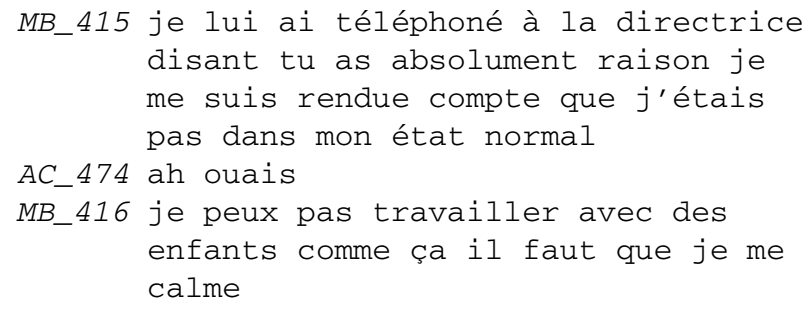

Ex7_En (Figure 4):

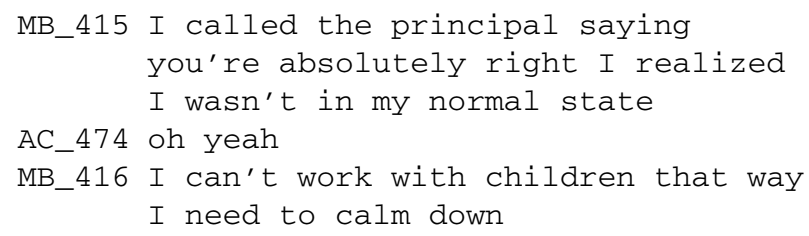

In sum, Ex5, 6 and 7 show ERS that is strongly oriented toward the previous turn: the ERS utterances are aligned in supporting the storytelling activity in progress and in completing the discursive devices used (dislocated and enumerative structures). For enumerative structures, the degree of convergence depends on the storyteller's possible orientation on the added item. 


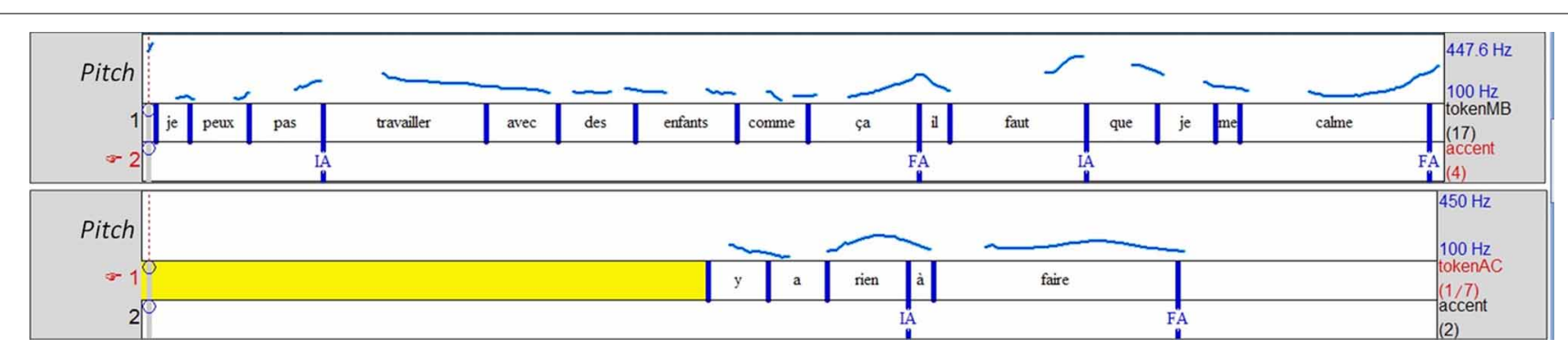

FIGURE 4 | Prosodic matching of the accentual arch (bounded by an initial accent IA or LHi and a final accent FA or $\mathrm{H} * / \mathrm{L} *$ on part of the utterance). By using the same scale $(100-550 \mathrm{~Hz}$ for the different speakers) we can see that the storyteller (top two lines) is producing the same accentual configuration with an expanded span (second occurrence) while the listener (bottom line) is producing the same one but in a very compressed span. The reiteration (by the storyteller) of the same configuration and the prosodic matching (by the listener) both contribute creating a list effect.

\section{Relying on introductory formula}

Our data present other cases illustrated by Ex8 and 9. When the storyteller produces an introductory formula for his/her reported speech, the listener can then rely on that formula or on the discourse particle that begins the reported speech, to produce reported speech using the same voice as the introductory formula.

In the example below (Ex8), $A B$ is telling a story about running a red light, and she is about to report the thoughts that she and her friends had at one point in the story. She produces an introductory formula, "on se dit/we think," and then the discourse marker "bon/well"; CM then produces an ERS (line 366): it is aligned (adapted to the narrative), and it is also adapted to the device. It fits perfectly with the storyteller's introduction, and it reports the supposed thoughts of $\mathrm{AB}$ and her friends. Not only is the element not ratified but especially $\mathrm{AB}$ orients toward her own idea, and consequently creates a repair sequence by repeating her own introductive formula. Therefore, despite CM's attempt to match $\mathrm{AB}$ 's stance, her response is not affiliative.

Ex8_Fr:

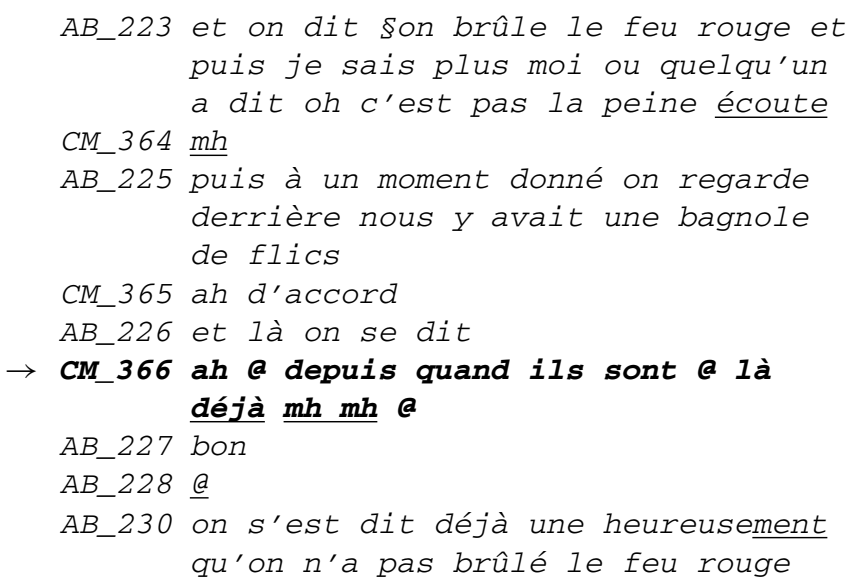

Ex8_En:

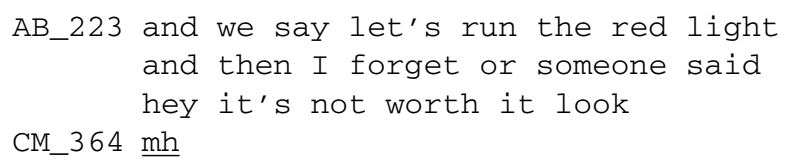

AB_225 then at one point we look behind us and there was a cop's car

CM_365 oh okay

AB_226 and then we think

$\rightarrow$ CM_366 oh a + how long have they a been there $\mathrm{mh} \mathrm{mh}$ a

AB_227 well

AB_228 트

AB_230 we thought first luckily we didn't run the red light

The next example (Ex9, Figure 5) shows a very similar case in terms of form. Here, CM is telling a story about how her ski broke when she was skiing. At this point in the story, CM is about to produce reported speech about her own thoughts. She produces an introductory formula, and the discourse marker "mais/but," which $\mathrm{AB}$ immediately follows with ERS using the same voice to show that she is reporting CM's thoughts. After a long pause of $700 \mathrm{~ms}$, which is visible on Figure 5, both participants simultaneously attempt to complete the thoughts initiated by the introduction of the reported speech: CM utters "mais/but" just as $\mathrm{AB}$ produces a click (relevant cue for taking the floor, circled in Figure 5).

The difference from the previous example is evident in the listener's change of tonality (i.e., the proposal of a "mood for the joke," Norrick, 2000: 174). This is a case of completion used to make fun of someone. While apparently reporting CM's thoughts, $\mathrm{AB}$ takes some distance from the normal strand of the story, and she displays a faint affiliation. The mocking tonality of the utterance apparently makes the sequence disaffiliative ( $\mathrm{AB}$ knows that $\mathrm{CM}$ did not break her ski on purpose). In fact, the humorous dimension of the ERS allows her to make fun but also to make evident the absurdness of the situation described by $\mathrm{CM}$. So in doing this, $\mathrm{AB}$ tells $\mathrm{CM}$ that her story was actually an unusual event, and consequently, CM actually correctly achieves the instructions given for the task, and $\mathrm{AB}$ has the same opinion as CM concerning the events: it is an unusual/absurd story. In the following turn the speaker ratifies the mockery ("ouais voilà/yeah there"), then goes back to the normal strand of the narrative. The reversal of roles that contributes to defining convergence in this paper is clearly illustrated by this example: $\mathrm{AB}$ takes the turn and thereby becomes the temporary main speaker. This change is also 


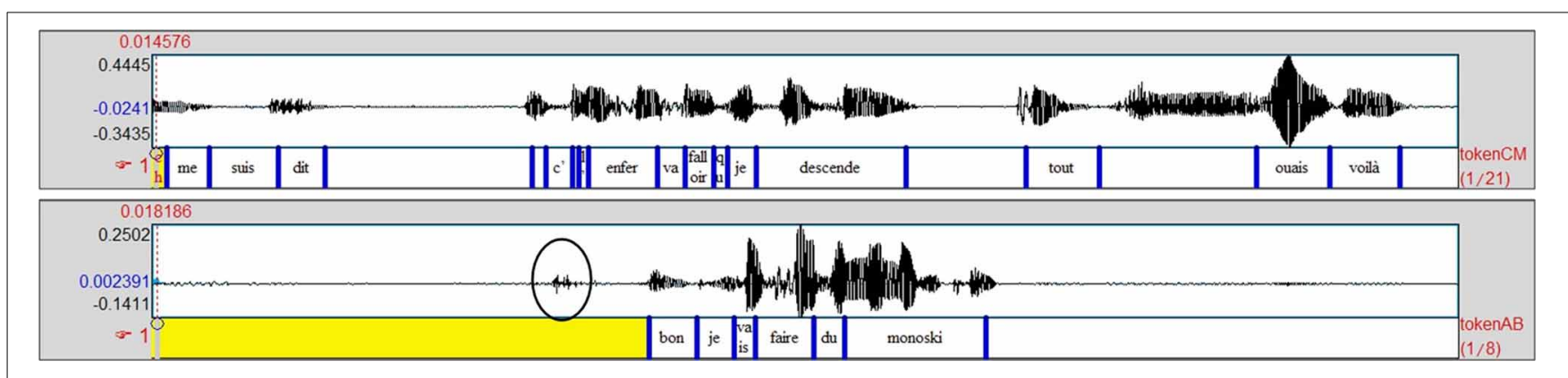

FIGURE 5 | Simultaneous reported speech from the storyteller and the listener.

obvious at the gestural level (see Figure 1) where the behaviors are reversed: in Figure 1C, AB (left) looks away and produces a large illustrative gesture during her ERS, whereas CM (right) directs her gaze at $\mathrm{AB}$ and stops moving. This results in a local convergence sequence.

Ex9_Fr (Figures 1, 5):

CM_463 et en fait euh le problème c'est que si tu peux plus du coup je pouvais plus chausser j'étais tout en haut de la station je pouvais plus chausser me suis dis mé(0.700)

CM_465 mais $C^{\prime}$ est $I^{\prime}$ enfer va falloir que je descende

$\rightarrow$ AB_294 CLIC bon je vais faire du monoski CM_466 tout euh ouais voilà

CM_467 ou euh donc en fait j'ai déchaussé

Ex9_En (Figures 1, 5):

CM_463 and in fact uh the problem is that if you can't do it anymore so I couldn't put them on anymore I was way above the station I couldn't put them on anymore I thought mé(0.700)

CM_465 but this is hell I'll have to go down

$\rightarrow$ AB_294 CLICK right well I'm going monoskiing CM_466 all uh yeah there

CM_467 or uh so in fact I took them off

\section{Reporting other voices}

In the next section, the listener produces ERS which reports other voices. This creates a reported dialogue between the characters in the story: the listener transforms an isolated occurrence of reported speech into a reported dialogue involving different voices.

In the next example (Ex10), CM is telling a story from her childhood, when she got confused between a dummy and a real employee in a store. She reports that the lady said "bonjour/hello," which was very surprising to her, because she thought that it was a plastic mannequin. She gives many cues of her own stance toward the events, speaking for instance of a "moment de peur/scary moment." This ERS constitutes an aligned and affiliative response to the story. Moreover, in this sequence, the participants are both strongly involved in the activity (high intensity of speech, loud laughing). It appears as a convergent moment in the interaction.

Ex10_Fr:

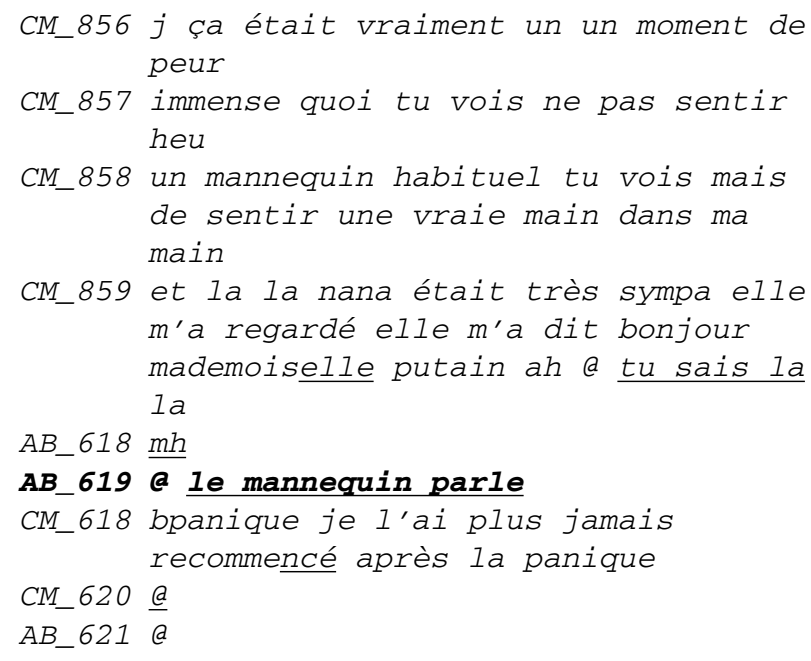

Ex10_En:

CM_856 I it was really a scary moment

CM_857 huge you know not to feel uh

CM_858 a normal dummy you see but to feel a real hand in my hand

CM_859 and the the lady was very nice she looked at me she said hello miss fuck oh a you know the the

AB_618 $\mathrm{mh}$

$\rightarrow$ AB_619 a the dummy talks

CM_618 bpanic I never did that again the panic

CM_620 믐

AB_621 a

Making complaints or telling amusing stories makes it possible for the participants to employ a humorous tonality (Bertrand and Priego-Valverde, 2011). Some stories are told entirely in a humorous way. We now examine an example of this kind: the 
setup is similar as in the previous example, but here it occurs in a humorous sequence.

Example 11 presents an instance of humorous reported speech that appears in a humorous story. The listener adopts the same tonality, so the response is aligned with the activity but also adapted to the tonality. LJ is telling a story about some strange men he met who he thought were going to kill him. This is a cue for his stance about the characters and the story. AP then produces ERS which "reports" the men's offer. To do this, AP uses the same word as LJ used in the penultimate turn, "prospectionprospecter/exploring." This is a way of showing his orientation toward the previous sequence. The verbal content and the stance AP displays are the same as the one that LJ expressed in the previous turn (430): "ils vont me tuer/they're going to kill me," but AP has used a new voice to reflect LJ's stance.

The participants previously built a humorous sequence, characterizing the enunciator as a "voileur $d u$ bois/rapist of the woods." In their study about prosody and humor, Bertrand and Priego-Valverde (2011) established, for this same excerpt, that the ERS uses a stereotyped voice linked to the characterization. The humorous dimension of the excerpt causes overbidding, in which the stance is "exaggerated." It still constitutes a highly affiliative response, and the laughter produced by both speakers are a cue to this interpretation. The humorous dimension of the listener's production is recognized by the storyteller, who ratifies it. Then the participants go back to the main activity in which they were engaged: LJ's storytelling. We thus, consider this to be a convergent sequence.

Ex11_Fr:

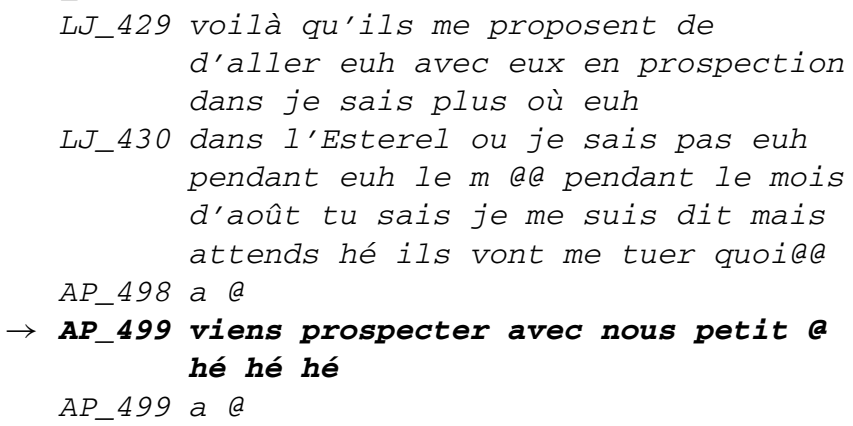

Ex11_En:

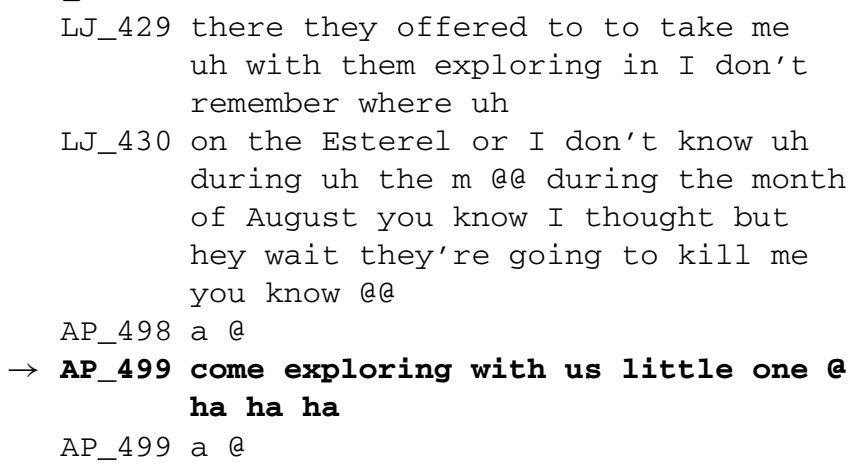

Example 11 appears in a sequence already established as humorous. In the next cases, ERS appears after reported speech and is used as a way of introducing a humorous tonality into a sequence which had a "neutral" tonality up to that point. We examine these examples in a separate subsection because the relevant information is not primarily the voice used, but the fact that the listener distances him/herself from the story and produces a response that introduces an "enunciative source" other than his/her own voice.

\section{Introducing a new tonality}

Example 12, AB is telling a story in which a friend of hers fell down. She reports what the friend said in a reported dialogue and then what she and her friends answered. After giving specific evaluative responses, CM produces ERS- "tu peux crever/you can drop dead"- that overbids "on se casse/we're outta here." Despite its similarity to Example 5 (same speaker in the same narrative), this ERS is not ratified by the storyteller. This may be due to the fact that CM's language was too strong; she authorizes this language by using a humorous tonality, but $\mathrm{AB}$ does not judge it to be acceptable or include the response in her story. Therefore, this is not an affiliative response.

Ex12_Fr:

AB_214 il était à moitié allongé par terre avec sa jambe comme ça en disant oh j'ai mal j'ai mal j'ai mal + on a dit on $s^{\prime}$ en fout on se barre et tout alors il a quand même réussi

CM_354 a oh putain excellent a

$\rightarrow$ CM_356 tu peux crever

$A B \_217$ il a quand même réussi à nous suivre

Ex12_En:

AB_214 he was halfway stretched out on the ground with his leg like that saying oh it hurts it hurts + we said we don't care we're outta here and all well he still managed

CM_354 a oh shit great a

$\rightarrow$ CM_356 you can drop dead

AB_217 he still managed to follow us

As often acknowledged, even in a very cooperative interaction such as a conversation, instances of competition or disagreement can appear. Until this point in the analysis, we have considered sections in which participants agreed. However, ERS can also appear in sequences of disagreement.

In the following example (Ex13), LJ is telling a story about archeological digs, which AP negatively evaluates by summarizing the story in an absurd way. From this point on, then they disagree. LJ tries to explain the reasons why the dig is not a scam. He uses reported speech to describe the content of a "diplôme/diploma" given to participants. AP then produces two occurrences of ERS $(421,422)$, simulating the content of the diploma and reformulating what LJ has just said. Each of AP's reported speech occurrences takes a humorous, mocking tone. Not only is there no affiliation in this case, since they do not express the same stance, but there is disaffiliation between participants since their stances are radically opposed. As we can see 
here, although ERS is generally used by participants in order to (attempt to) affiliate, it can also be used in an oblique way to show disaffiliation.

Ex13_Fr:

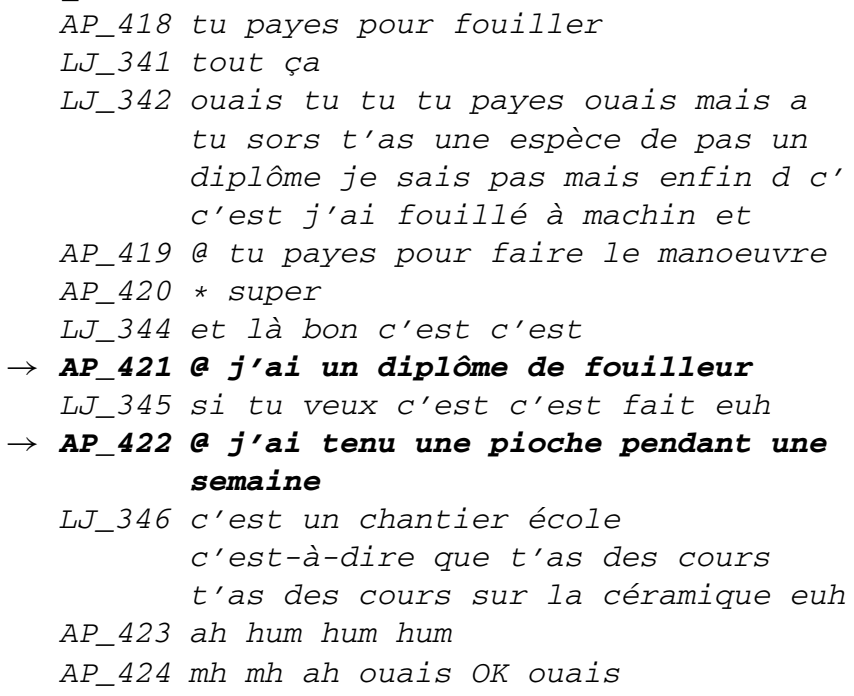

In most cases, ERS appears in the close environment of reported speech from the storyteller. It frequently follows (or is produced simultaneously with) the storyteller's reported speech, but occasionally it can anticipate it.

\section{Anticipating a reported speech utterance}

In Example 14, the storyteller ML is not currently producing reported speech. She describes an attitude of the characters in her story by using "genre/a sort of" (675). More than an introductory formula, "genre" carries a type of representation of the "animated character" (Couper-Kuhlen, 1999) that can infer a type of stance ("dégoûtés/disgusted"). IM repeats "genre," and relies on it to reformulate the adjective "dégouté" into direct reported speech, corresponding to the same critical stance toward the attitude described by ML. Even though ML is not reporting speech at this point, there are still similarities in the content and structure ("genre"). As reported speech from the storyteller elicits ERS in other cases, "genre" (produced by the storyteller) here elicits ERS, which ML ratifies with "ouais/yeah." Although ML does not produce reported speech before the ERS, she does so in the following utterance. In this case, ERS could encourage the storyteller to use reported speech. This is a local convergent sequence.

Ex14_Fr:

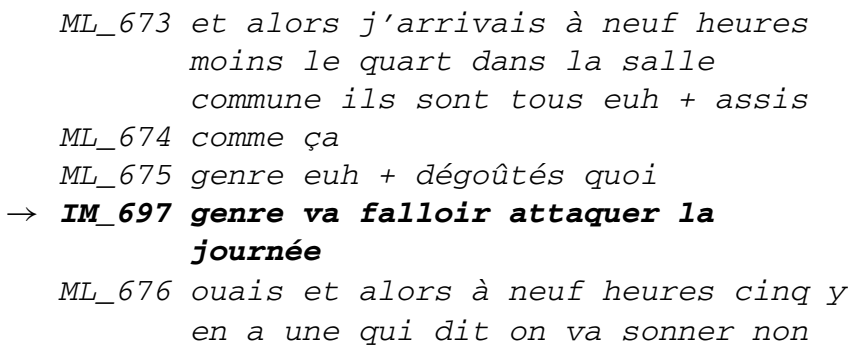

Ex14_En:

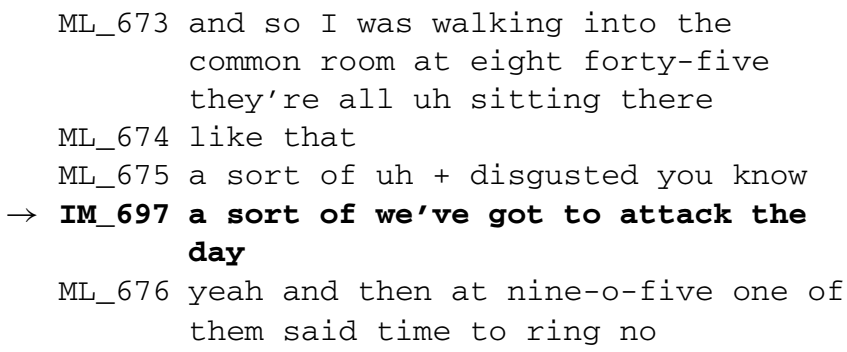

\section{Creating an oblique sequence}

In this subsection, ERS is used to initiate a new oblique sequence (Stivers, 2008). We show that it results in temporary disalignment, contrary to the previous examples.

In Example 15, LJ is telling a story in a neutral tone. AP produces an ERS utterance (line 844) using the voice of a fictitious psychoanalyst asking a question. This remark is presented as humorous and as non-aligned, considering the absurd scenario it brings to life. AP then continues to use a humorous tone, producing a second occurrence of ERS (line 845): an answer to the question, given by a fictitious patient. Then LJ continues and overbids on this topic, producing another question whose enunciator is still the fictitious psychoanalyst. At this point, he agrees to engage in this new activity of joint fantasy (Kotthoff, 2006), together with the listener, so that they re-align toward the new activity. By doing this, LJ orients more explicitly to the sexual dimension, while he refers to dialogues of a famous movie ("Airplane!"). AP then produces a new reported speech utterance, still from the same movie. Since the participants imagine the same situation together-a situation which has digressed from the normal frame of the story and which includes shared knowledge-they show affiliation. After this oblique sequence, they go back to the initial activity of storytelling.

The humorous sequence is constructed from the listener's initiation of an oblique sequence, which causes disalignment from the current activity. The storyteller's realignment with this new activity leads to their co-elaboration of a highly 
affiliative sequence resulting in a highly convergent sequence overall.

Ex15_Fr:

LJ_778 fait un truc tu sais un vague contour quoi et ça ressemblait à un oiseau photocopié quinze mille fois un peu colorié

LJ_779 tu dis mais attends un gamin il fait ça déjà tu lui files deux baffes quoi

AP_844 qu'est-ce que ça t'évoque

AP_845 eh ben là disons que euh je pense plutôt à ma mère euh

LJ_780 et euh et

$A P \_846$ e et à mon attirance euh

LJ_781 et en plus euh tu aimes les films de gladiateurs $a$

AP_847 oui as-tu déjà été dans les bains turcs euh

Ex15_En:

LJ_778 do something ya know a rough outline like that looked like a bird photocopied fifteen thousand times a little colored in

LJ_779 you say but wait if a kid does that you know you'd slap him twice like

AP_844 what does that remind you of

AP_845 well there let's say that uh I think of my mother uh

LJ_780 and uh and

$\mathrm{AP}$ 846 a and of my attraction uh

LJ_781 and plus uh you like gladiator movies

AP_847 yes have you already been to a Turkish bath uh

In Example 16, SR is reporting his experience when he lived abroad: he expected to be treated as a foreign agent (to be reimbursed more quickly, because foreign agents are not registered in the computer files). But he was treated as a French agent. In turn 680, EB produces a specific response "et donc tu étais français/so you were French," which can be considered as a completion, oriented toward SR's previous turn. SR then reports his own reaction to the office's statement: "non/no" in turn 563. At this point, the participants begin to laugh and continue doing so until the end of the sequence. EB then completes the interjection reported by SR with ERS, while developing the idea: “c'est un autre/that's somebody else." Reporting what SR could have said in this situation, EB displays his understanding of the situation and his affiliation. SR then produces "je suis de Glasgow/I'm from Glasgow," which does not orient toward EB's turn but is a completion of his own previous turn. EB then continues the idea SR has just introduced: "Simon Rivière" is an ERS utterance produced with a phonetic modification, a cue to code-switching. SR then also produces reported speech in which he uses the same accent and the English words "from Glasgow University," consequently orienting toward EB's turn. EB then repeats "from Glasgow," again showing alignment. In turn 566, SR produces reported speech which is then followed by EB's very similar turn, which he begins with the same structure, "that's not the."

This alignment and affiliation results in a highly convergent sequence in which ERS is associated with other devices, such as lexical similarity (other-repetition), language similarity (codeswitching), syntactic similarity, and much loud and long laughter (@). These various devices display affiliation (see Bertrand and Priego-Valverde, 2011 for prosodic matching). This sequence is co-elaborated to such a degree that the participant's roles are confused. In contrast to the asymmetry of the previous story, the oblique sequence here exhibits symmetry of roles in which either participant could be the main speaker.

Ex16_Fr:

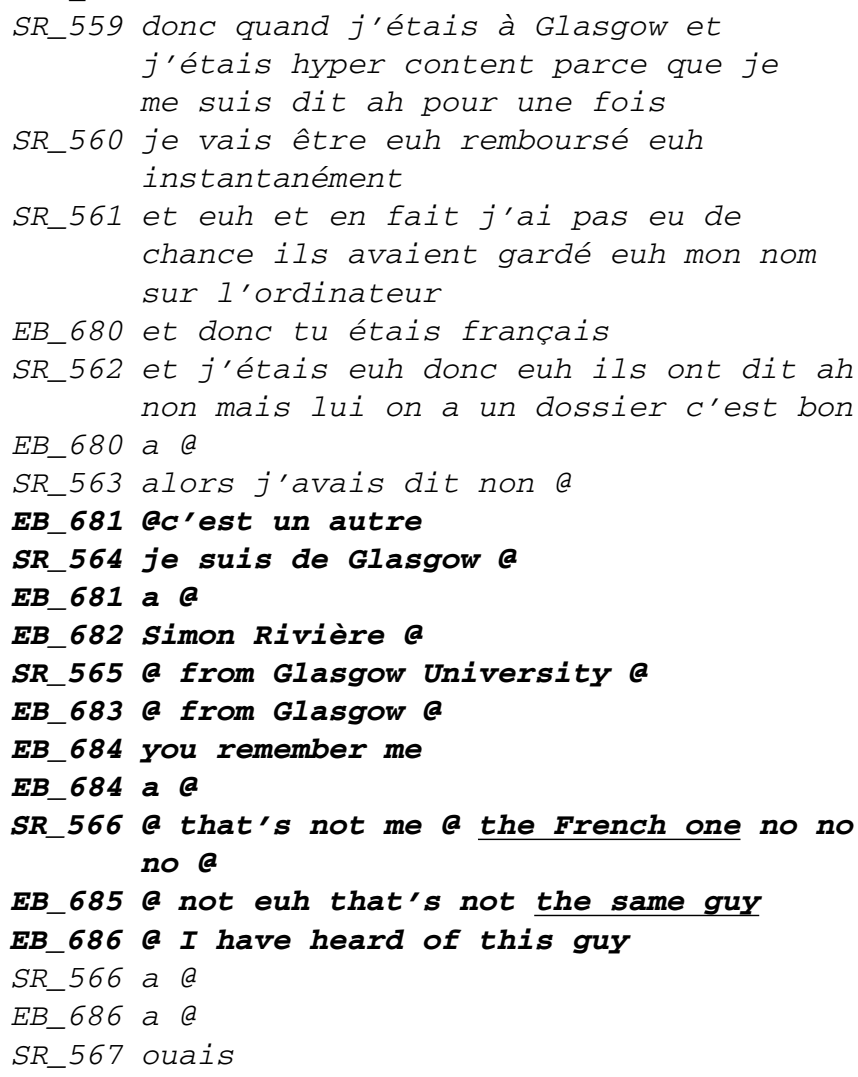

Ex16_En:

SR_559 so when I was in Glasgow and I was ultra happy because I thought oh for once

SR_560 I'm going to be uh paid uh instantly

SR_561 and uh and in fact I didn't have a chance they had kept uh my name in the computer

EB_680 and so you were French

SR_562 and I was uh so uh they said ah no but we have his file it's ok

EB_680 a a

SR_563 so I said no a

EB_681 a that's somebody else

SR_564 I'm from Glasgow a

EB_681 a e 


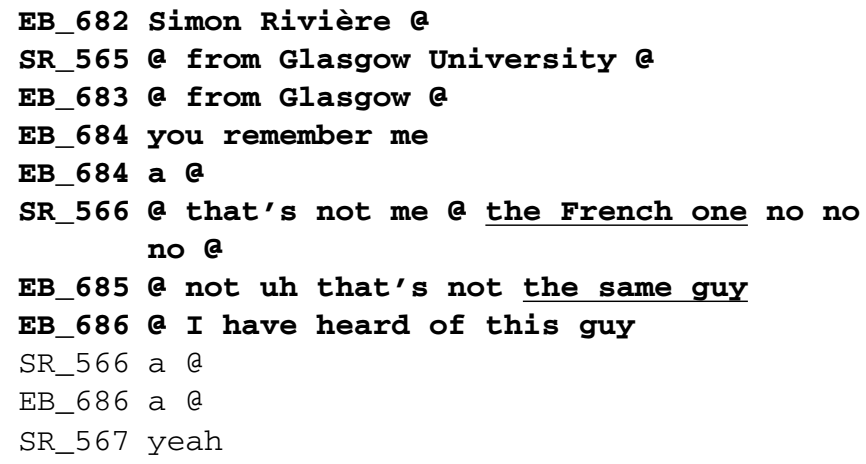

Lastly, in some cases, the listener repeats reported speech produced by the storyteller. These other-repetitions can take similar forms as ERS.

Example 17 presents a story told by $\mathrm{AB}$. She reports a reported exchange between herself and a friend of hers. CM repeats what $\mathrm{AB}$ has just said. However, this is not a case of ERS, even if the use of deixis is consistent with the story being told, and not with the situation in which the participants are being recorded. Since $\mathrm{AB}$ has just uttered exactly the same sentence, the second turn is a repetition, with a "savoring" evaluative function (Tannen, 1989, 2007). The listener does not provide a stance toward the events but rather an evaluation of AB's words themselves. Consequently, we cannot infer any consequences about affiliation.

Despite their similar forms, other-repetition is different from ERS in the sense that it appears in second position: the element that is repeated has already been produced by the main speaker, and it is not invented by the listener thanks to shared knowledge.

Ex17_Fr:

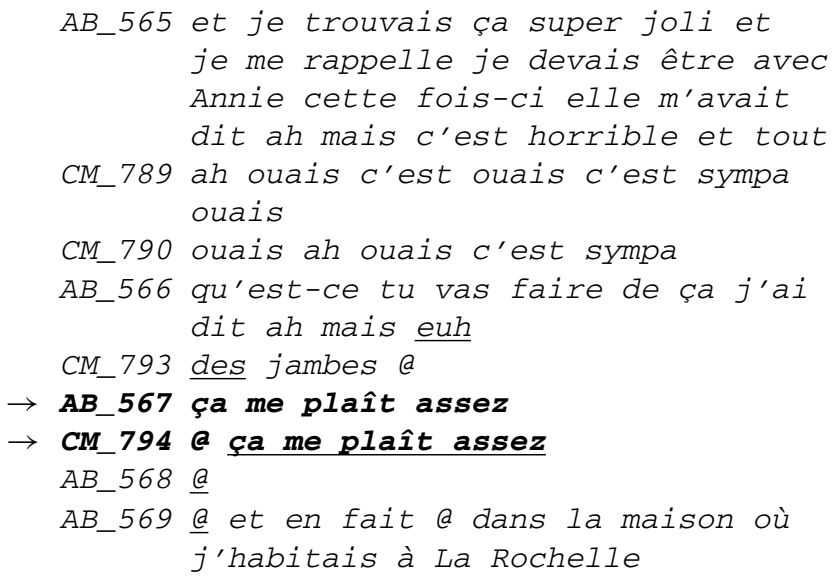

Ex17_En:

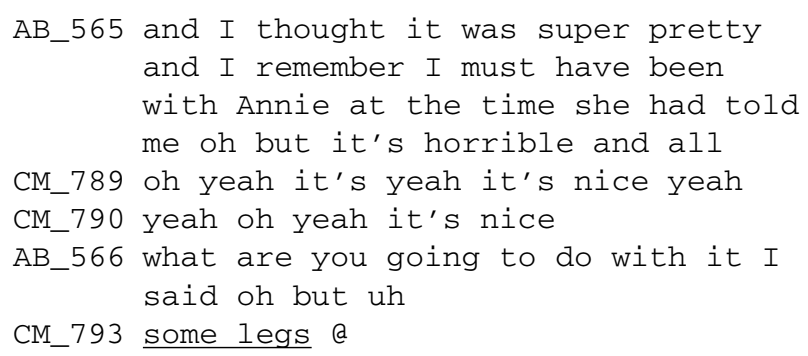

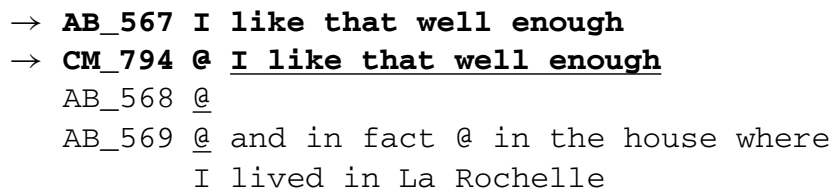

\section{DISCUSSION}

In this paper we examined how participants in conversation build convergent sequences in accordance with the concepts of alignment and affiliation (Stivers, 2008). We highlighted a type of specific response (Bavelas et al., 2000) expressed by the listener in storytelling. This specific response is a kind of reported speech that occurs during a narrative and that we term "Echo Reported Speech" (ERS), insofar as it is produced as an "echo" to the ongoing narrative. Usually, reported speech is a device used by the storyteller to report not only words but also thoughts (Klewitz and Couper-Kuhlen, 1999) to achieve certain goals during talk-in-interaction. We showed here that when the storyteller had given enough information, the listener could produce ERS him/herself by which she/he could display (dis)alignment and (dis)affiliation in orienting respectively, to the current activity and the expected stance. Moreover, the use of reported speech by the listener represents a change of discursive role that is also of crucial importance to the study of convergence: reporting speech consists of producing words that have been said in another situation. Since the listener cannot have heard these words before, his/her reported speech (invented) provides evidence that he/she is temporarily taking the place of the main speaker.

Following Stivers (2008) alignment pertains to the activity being carried out by the participants of an interaction. Affiliation concerns the stance of participants: a response that displays the same stance as that of the other participant is an affiliative response. ERS signals alignment: it constitutes an adapted response, presented as specific to the ongoing narrative. In many cases, the storyteller him/herself elicits this type of response. Holt (2000) argues that because of its double function, direct reported speech allows the "reporter" to appear to accurately report the speech of another speaker, while simultaneously commenting upon the reported utterance. In doing so, he/she implicitly displays his/her own stance and elicits an explicit display of that stance by the listener. Following Stivers (2008), displaying the same stance as the other participant is an affiliative response. Listeners producing ERS thus, display their stance toward the story being told.

In other cases, ERS is used for alignment and affiliation when the listener displays a stance similar to the storyteller's. These sequences are potential places for the emergence of convergent sequences. Alignment without affiliation occurs in cases where the main speaker does not react to the ERS in the following turn, but continues his/her own narration with no explicit sign (verbal, laughter) of an orientation toward the listener's production.

Finally, disalignment linked to a change of activity (as in a humor sequence) can be associated with affiliation and lead to highly convergent oblique sequences, such as Joint Fantasy. Alternatively, this type of sequence can fail to lead to affiliation, in which case it results in a lack of convergence. 
In this study of convergence phenomena, we did not discuss the concept of similarity between one participant's production and that of the other participant. Similarity and convergence are often considered synonymous. We argue from an interactional point of view that while the various manifestations of similarity can point to convergence, convergent sequences take on a much greater variety of forms, due to the different activities deployed and the participant's differing roles, among other things (see Bertrand et al., 2013, to show that "gestural" similarity is not sufficient to describe convergence). However, ERS itself can be seen as a type of similarity, in the sense that it co-occurs with Reported Speech in such a way that both participants use the same discursive device. Moreover, similarity can also be observed through the use of voices: the listener uses the same voice as the one animated by the storyteller in his/her own story.

Tannen $(1989,2007)$ argues that "when a listener utters a line of dialogue for a story she isn't telling, that dialogue certainly cannot be considered reported." But if we take the delivery of ERS into account (change of verb tense, matching use of personal, spatial, and temporal deictics relevant to the narrative rather than the situation) into account, ERS appears as a type of reported speech. Moreover, from an interactional point of view, producing reported speech is a way of representing an encounter between individuals. In ERS, the listener represents an encounter he/she has not witnessed. But ERS is an invention, and as in every type of invented reported speech, the encounter described is a fictitiously anchored one. ERS consists of reporting the speech that a character could have said in a precisely defined situation. The listener has understood the story told so well that he/she is totally aligned and becomes able to produce speech that a character of the story could have said. This invented reported speech is however, consistent with Vincent and Dubois' definition (1997) of invention reported speech even though these authors only consider the storyteller's point of view. Ultimately, whether the status of ERS is reported speech or not, it would still appear as an aligned and/or affiliative response, and it would have the same consequences on the sequence's degree of convergence.

More generally, in highly convergent sequences, ERS is often associated with many other similarity based devices (otherrepetition, prosodic matching, simultaneous laughter, etc.). This highlights the complexity of the convergence phenomena that the notions of alignment and affiliation enable us to capture. Such an interactional orientation framework provides insight into interactional convergence. Moreover, a sequential analysis supplies some cues for gaining access to expressed opinions and thoughts, which are studied using cognitive models. Among these models, Pickering and Garrod (2004) proposed a psychological model of interactional alignment in which the alignment of mental representations has consequences on alignment at several linguistic levels. The alignment of representations is a requirement for successful interaction. In a conversation, for example, if the participants have aligned their representations, their linguistic utterances will be aligned too (phonetically, syntactically, and semantically). In any case, participants who try to align may fail, in which case they can use repair sequences to establish alignment. Finally if they still do not manage to align their representations, they begin to explicitly talk about the misalignment in order to resolve it. In this context, the contribution we present here provides support for this model: using the same discursive device as the main speaker is a way for the listener to align at the interactional level. When displaying affiliation, the ERS allows the listener to express his/her own stance toward the events. It consequently can be a way of expressing opinions or representations.

The relationship between affiliation and alignment is highlighted by Stivers (2008), who assumes that affiliation requires alignment. The author explains that since affiliation means that the listener knows which stance the teller has toward his/her own story and knows that a similar stance is the preferred response, the participant has received enough information to be able to produce the affiliative response, which necessarily occurs after he/she has understood the story (exhibited by the alignment). However, in some of our examples (Joint Fantasy, among others) affiliation co-occurs with disalignment. This appears to contradict Stivers' argument that alignment is required before affiliation. But in fact, in the cases we observed, the main speaker tells a story, to which the listener aligns (thanks to generic responses). At a certain point in the story, the listener produces a disaligned response, which constitutes a proposal to change the activity. The storyteller can refuse this proposal of an oblique sequence: in that case, the disalignment caused by the humorous ERS, for example, is effective and needs to be resolved by the listener him/herself, who then realigns, going back to the previous activity of listening to the story. In these cases, there is a lack of convergence. But in other cases, the storyteller accepts the oblique scenario and consequently agrees to temporarily set aside his/her narrative. Meanwhile, the storyteller (who is no longer the main speaker) aligns with the new activity proposed by the listener. We have mainly observed this kind of sequence in Joint Fantasy (Kotthoff, 2006). It is not surprising that highly convergent sequences co-occur with humor, since alignment and complicity are prerequisites of humor.

Concerning the turn-taking organization, ERS also plays a role that affects convergence. Conversation is a symmetrical interaction in which participants play symmetrical roles: the differences between speakers are minimized. No differences in their status in the interaction are created $a$ priori. But in the activity of storytelling, the roles are highly asymmetrical: each participant has to accomplish different tasks, conditioned by their role as storyteller or as listener. We show here that ERS causes a change in roles: the listener produces reported speech -which is normally a device used by the main speaker-, thereby temporarily taking the main speaker's place. This role change decreases the differences between the participants and contributes to the potential emergence of convergent sequences. In the case of highly convergent sequences such as humorous ones, the participants no longer hold two asymmetrical roles at all.

Joint fantasy is the most convergent sequence in this context, which includes the task in which the participants are involved, the relationship between them, and also the cultural context. In some cultures, symmetry between participants is not conceivable. In other cultures (Danziger, 2006) fantasy may not be the preferred sequence: alignment and affiliation, together with the 
symmetrical status of participants, may result in another type of convergent sequence.

Finally, this study demonstrates the importance of clearly defining the notion of convergence in conversational data. This notion, apparently easy to capture through the notion of similarity, cannot be reduced to a single concept. Both alignment and affiliation are relevant notions for describing convergence phenomena. By investigating other specific responses, we are currently enriching our description of the recipient design in terms of alignment/affiliation. This leads us to improve our understanding of interactional convergence and more generally the organization of conversations.

\section{REFERENCES}

Barth-Weingarten, D., Reber, E., and Selting, M. (2010). Prosody in Interaction. Amsterdam: John Benjamins Company.

Bavelas, J. B., Coates, L., and Johnson, T. (2000). Listeners as co-narrators. J. Pers. Soc. Psychol. 79, 941-952. doi: 10.1037/0022-3514.79.6.941

Bertrand, R., Blache, P., Espesser, R., Ferré, G., Meunier, C., Priego-Valverde, B., et al. (2008). Le CID-Corpus of Interactional Data-Annotation et Exploitation Multimodale de Parole Conversationnelle. Traitement Automatique des Langues 49, 105-134.

Bertrand, R., Ferré, G., and Guardiola, M. (2013). "French face-to-face interaction: repetition as a multimodal resource," in Coverbal Synchrony in Human-Machine Interaction, eds $\mathrm{N}$. Campbell and M. Rojc (Enfield, New Hampshire: Science Publishers), 30.

Bertrand, R., and Priego-Valverde, B. (2011). Does prosody play a specific role in conversational humor? Pragmat. Cognit. 19, 333-356. doi: 10.1075/pc.19.2.08ber

Blache, P., Bertrand, R., and Ferré, G. (2009). "Creating and exploiting multimodal annotated corpora: the ToMA project," in Multimodal Corpora. From Models of Natural Interaction to Systems and Applications, eds M. Kipp, J. C. Martin, P. Paggio, and D. Heylen, (Berlin; Heidelberg: $\quad$ Springer-Verlag), 38-53.

Blache, P., Bertrand, R., Guardiola, M., Guénot, M. L., Meunier, C., Nesterenko, I., et al. (2010). "The OTIM formal annotation model: a preliminary step before annotation scheme," in Proceedings of Language Resource and Evaluation Conference (2010 mai 19-21: La Valette, MALTA), 3262-3267.

Blondal, P. (2005). "Feedback in conversational storytelling," in Feedback in Spoken Interaction, ed J. Allwood (Nordtalk: Gothenburg Papers in Theoretical Linguistics), 1-17.

Boersma, P., and Weenink, D. (2009). Praat: Doing Phonetics by Computer (Version 5.1.05) [Computer program]. Available online at: http://www.praat.org/

Bolden, G. (2004). The quote and beyond: defining boundaries of reported speech in conversational Russian. J. Pragmat. 36, 1071-1118. doi: 10.1016/j.pragma.2003.10.015

Clark, H. H. (1996). Using Language. Cambridge: Cambridge University Press. doi: 10.1017/ CBO9780511620539

Couper-Kuhlen, E. (1999). "Coherent voicing: on prosody in conversational reported speech," in Coherence in Spoken and Written Discourse: How to Create It and How to Describe It, eds W. Bublitz and U. Lenk (Amsterdam: Benjamins), 11-32.

Couper-Kuhlen, E., and Selting, M. (eds.). (1996). Prosody in Conversation. Cambridge: Cambridge University Press. doi: 10.1017/CBO9780511597862

Danziger, E. (2006). "The thought that counts: understanding variation in cultural theories of interaction," in The Roots of Human Sociality: Culture, Cognition and Human Interaction, eds S. P. Levinson and N. Enfield (New York, NY: Berg Press), 259-278.

Di Cristo, A. (1999). Le cadre accentuel du français: essai de modélisation. Langues 2, 3, 4, 184-205 and 258-269.

Fonagy, I. (1979), “L'accent en français: accent probabilitair in L'accent en français contemporain," in Studia Phonetica, eds I. Fonagy and P. Léon (Paris: Didier), 123-233.

Fox Tree, J. E. (1999). Listening in on monologues and dialogues. Dis. Process. 27, 35-53. doi: 10.1080/ 01638539909545049

Guardiola, M., Bertrand, R., Espesser, R., and Rauzy, S. (2012). "Listener's

Transcription conventions:

\author{
@: laughter \\ @@...@@: laughing sequence \\ Underlining: overlapping speech \\ (0.25): duration of pause (in seconds).
}

\title{
ACKNOWLEDGMENTS
}

This study was carried out as part of the SPIM (ANR-08-BLAN0276) and OTIM (ANR-08-BLAN-0239) projects, funded by the Agence Nationale de la Recherche. We are grateful to the reviewers for their helpful comments on previous version of this paper.

responses during storytelling in French Conversation," in Proceedings of Interdisciplinary Workshop on Feedback Behaviors in Dialog (Stevenson), 6.

Günthner, S. (1999). Polyphony and the «layering of voices》 in reported dialogues: an analysis of the use of prosodic devices in everyday reported speech. J. Pragmat. 31, 685-708. doi: 10.1016/S0378-2166(98)00093-9

Holt, E. (1996). Reporting on talk: the use of direct reported speech in conversation. Res. Lang. Soc. Interact. 29, 219-245. doi: 10.1207/ s15327973rlsi2903_2

Holt, E. (2000). Reporting and reacting: concurrent responses to reported speech. Res. Lang. Soc. Int. 33, 425-454. doi: 10.1207/S15327973RLSI3304_04

Hutchby, I., and Wooffitt, R. (1998). Conversation Analysis. Cambridge: Polity Press.

Jefferson, G. (1978), "Sequential aspects of storytelling in conversation," in Studies in the Organization of Conversational Interaction, ed J. N. Schenkein (New York, NY: Academic Press), 219-248.

Jefferson, G. (1990). "List-construction as a task and resource," in Interactional Competence, ed G. Psathas (New York, NY: Irvington Publishers), 63-92.

Kern, F. (2007). Prosody as a resource in children's game explanations: some aspects of turn construction and recipiency. J. Pragmat. 1, 111-133. doi: 10.1016/j.pragma.2005.01.017

Klewitz, G., and Couper-Kuhlen, E. (1999). Quote-unquote? the role of prosody in the contextualization of reported speech sequences. Pragmatics 9, 459-485.

Kotthoff, H. (2006). Oral genres of humor: on the dialectic of genre knowledge and creative authoring. Int. Linguist. Struct. 44, 263-296.

Labov, W., and Waletzky, J. (1966). "Narrative analysis: oral versions of personal experience," in Essays on the Verbal and Visual Arts: Proceedings of the 1966 Annual Spring Meeting of the American Ethnological Society, ed J. Helm (Seattle: University of Washington Press), 12-44.

Mondada, L. (2013), "The conversation analytic approach to data collection," in The Handbook of Conversation Analysis, eds J. Sidnell and T. Stivers (Malden, MA: WileyBlackwell), 32.

Norrick, N. R. (2000). Conversational Narrative: Storytelling in Everyday Talk. Philadelphia, PA: John Benjamins.

Pickering, M., and Garrod, S. (2004). Toward a mechanistic psychology of dialogue. Behav. Brain Sci. 27, 169-190. doi: 10.1017/S0140525X04000056

Portes, C., Bertrand, R., and Espesser, R. (2007). Contribution to a grammar of intonation in french. form and function of three rising patterns. Nouveaux Cahiers de Linguistique Française 28, 155-162.

Sacks, H., Schegloff, H., and Jefferson, G. (1974). A simplest systematics for the organization of turntaking for conversation. Language 50, 696-735. doi: 10.2307/412243

Schegloff, E. A. (1982). "Discourse as an interactional achievement: some uses of "uh huh" and other things that come between sentences," in Analyzing Discourse: Text and Talk, ed D. Tannen (Washington, DC: Georgetown University press), 71-93.

Selting, M. (2000). The construction of "units" in conversational talk. Lang. Soc. 29, 477-517. doi: 10.1017/S0047404500004012

Selting, M. (2004). "The "upward staircase" intonation contour in the Berlin vernacular. An example of the analysis of regionalized intonation as an interactional resource," in Sound Patterns in interaction, eds E. Couper-Kuhlen and C. E. 
Ford (Amsterdam: John Benjamins Publishing Company), 201-232.

Selting, M. (2007). Lists as embedded structures and the prosody of list construction as an interactional resource. J. Pragmat. 39, 483-526. doi: 10.1016/j.pragma.2006.07.008

Selting, M. (2010). "Prosody in interaction: state of the art," in Prosody in Interaction, eds D. Barth-Weingarten, E. Reber, and M. Selting (Amsterdam: Benjamins), 3-40.

Selting, M., Auer, P., Barden, B., Bergmann, J., CouperKuhlen, E., Günthner, S., et al. (1998). Gesprächsanalytisches Transkriptionssystem (GAT)'. Linguistische Berichte 173, 91-122.
Stivers, T. (2008). Stance, alignment, and affiliation during storytelling: when nodding is a token of affiliation. Res. Lang. Soc. Interact. 41, 31-57. doi: 10.1080/08351810701691123

Szczepek Reed, B. (2006). Prosodic Orientation in English Conversation. Basingstoke: Palgrave MacMillan. doi: 10.1057/9780230625273

Szczepek Reed, B. (2010). Prosody and alignment: a sequential perspective. Cult. Stud. Sci. Educ. 5, 859-867. doi: 10.1007/s11422-010-9289-z

Tannen, D. (1989, 2007). Talking Voices: Repetition, Dialogue and Imagery in Conversational Discourse. Cambridge: Cambridge University Press.
Vincent, D., and Dubois, S. (1997). Le discours rapporté au quotidien. Québec: Nuit Blanche éditeur, coll. «Langue et pratiques discursives $\gg$

Conflict of Interest Statement: The authors declare that the research was conducted in the absence of any commercial or financial relationships that could be construed as a potential conflict of interest.

Received: 15 May 2013; accepted: 16 September 2013; published online: 08 October 2013.

Citation: Guardiola $M$ and Bertrand $R$ (2013) Interactional convergence in conversational storytelling: when reported speech is a cue of alignment and/or affiliation. Front. Psychol. 4:705. doi: 10.3389/fpsyg.2013.00705

This article was submitted to Cognitive Science, a section of the journal Frontiers in Psychology.

Copyright (c) 2013 Guardiola and Bertrand. This is an open-access article distributed under the terms of the Creative Commons Attribution License (CC BY). The use, distribution or reproduction in other forums is permitted, provided the original author(s) or licensor are credited and that the original publication in this journal is cited, in accordance with accepted academic practice. No use, distribution or reproduction is permitted which does not comply with these terms. 